\title{
Mesenchymal Stromal Cells Perspective: New Potential Therapeutic for the Treatment of Neurological Diseases
}

\author{
Takeo Mukai ${ }^{1,2, *(D)}$, Kenshi Sei ${ }^{2}$ and Tokiko Nagamura-Inoue ${ }^{2}$ \\ 1 Department of Pediatrics, The University of Tokyo Hospital, Hongo, Bunkyo-ku, Tokyo 113-8655, Japan \\ 2 Department of Cell Processing and Transfusion, The Institute of Medical Science, The University of Tokyo, \\ 4-6-1 Shirokanedai, Minato-ku, Tokyo 108-8639, Japan; k-sei@ims.u-tokyo.ac.jp (K.S.); \\ tokikoni@ims.u-tokyo.ac.jp (T.N.-I.) \\ * Correspondence: takeo-m@ims.u-tokyo.ac.jp; Tel.: +81-3-3815-5411; Fax: 81-3-5449-5452
}

Citation: Mukai, T.; Sei, K.; Nagamura-Inoue, T. Mesenchymal Stromal Cells Perspective: New Potential Therapeutic for the Treatment of Neurological Diseases. Pharmaceutics 2021, 13, 1159. https://doi.org/ $10.3390 /$ pharmaceutics 13081159

Academic Editor: Edorta

Santos-Vizcaino

Received: 2 July 2021

Accepted: 24 July 2021

Published: 27 July 2021

Publisher's Note: MDPI stays neutral with regard to jurisdictional claims in published maps and institutional affiliations.

Copyright: (c) 2021 by the authors. Licensee MDPI, Basel, Switzerland This article is an open access article distributed under the terms and conditions of the Creative Commons Attribution (CC BY) license (https:// creativecommons.org/licenses/by/ $4.0 /)$.

\begin{abstract}
Several studies have shown that mesenchymal stromal/stem cells (MSCs) exert their neuroprotective and neurorestorative efficacy via the secretion of neurotrophic factors. Based on these studies, many clinical trials using MSCs for the treatment of neurological disorders have been conducted, and results regarding their feasibility and efficacy have been reported. The present review aims to highlight the characteristics and basic research regarding the role of MSCs in neurological disease and to discuss the recent progress in clinical trials using MSCs to treat various neurological disorders.
\end{abstract}

Keywords: mesenchymal stromal cell; umbilical cord; neurological disorders; cerebral palsy; neurotrophic factor

\section{Introduction}

Mesenchymal stromal/stem cells (MSCs) have been the focus of new cell therapy development due to their potential to treat neurological disorders [1]. MSCs were first discussed in 1991 when they were introduced by Caplan as mesenchymal cells in bone marrow [2]. Now, MSCs have been isolated from several sources, including bone marrow (BM), the umbilical cord (UC), umbilical cord blood (UCB), dental pulp (DP), and adipose tissue (AD) [1,3-8].

The characteristics of MSCs are defined by a set of criteria that form the basis for their clinical use (Figure 1). The International Society for Cellular Therapy proposed the criteria for defining human MSCs $[9,10]$. Firstly, the MSCs must be plastic-adherent when maintained in standard culture conditions. Secondly, they must express CD105, CD73, and CD90, but not CD45, CD34, CD14 or CD11b, CD79 $\alpha$ or CD19, and HLA-DR surface molecules. Thirdly, MSCs must be able to differentiate into adipocytes, chondroblasts, and osteoblasts in vitro. Immunomodulatory effects are the most important and popular property of MSCs in their clinical use [11]. MSCs lack HLA-class II expression and do not express the co-stimulatory surface antigens CD80 or CD86, which activate T-cells [12]. As a result, these cells are able to escape from activated T-cells. MSC-mediated immunomodulation results from the MSC secretome, which includes components such as indoleamine 2,3-dioxygenase (IDO), PGE2, galectin-1, and HLA-G5 [13]. With these anti-inflammatory properties, MSCs could be useful therapeutic candidates for use in the treatment of neurological disorders accompanying inflammation.

The tissue repair properties of MSCs are also important to their neurorestorative effect. The neurorestorative and neuroprotective effects of MCSs regarding tissue repair can be divided into two main mechanisms: (1) neurogenic differentiation and eternal cell replacement and (2) the secretion of neurotrophic factors [14]. Regarding the former, we have observed in our experiments that MSCs do not engraft and differentiate into neural cells, and they disappear within two weeks of administration in non-immunocompromised 
mouse models [15]. In contrast, we found that UC-MSCs that secrete neurotrophic factors such as brain-derived neurotrophic factor (BDNF) and hepatocyte growth factor (HGF) but not nerve growth factor (NGF) attenuate brain injury $[15,16]$. This MSC paracrine effect is expected to contribute toward their use in therapeutics for neurological injuries. Many studies using neurological disorder models have reported improvements in the studied conditions after the administration of MSCs, and clinical studies using MSCs to treat neurological disorders have been already conducted.

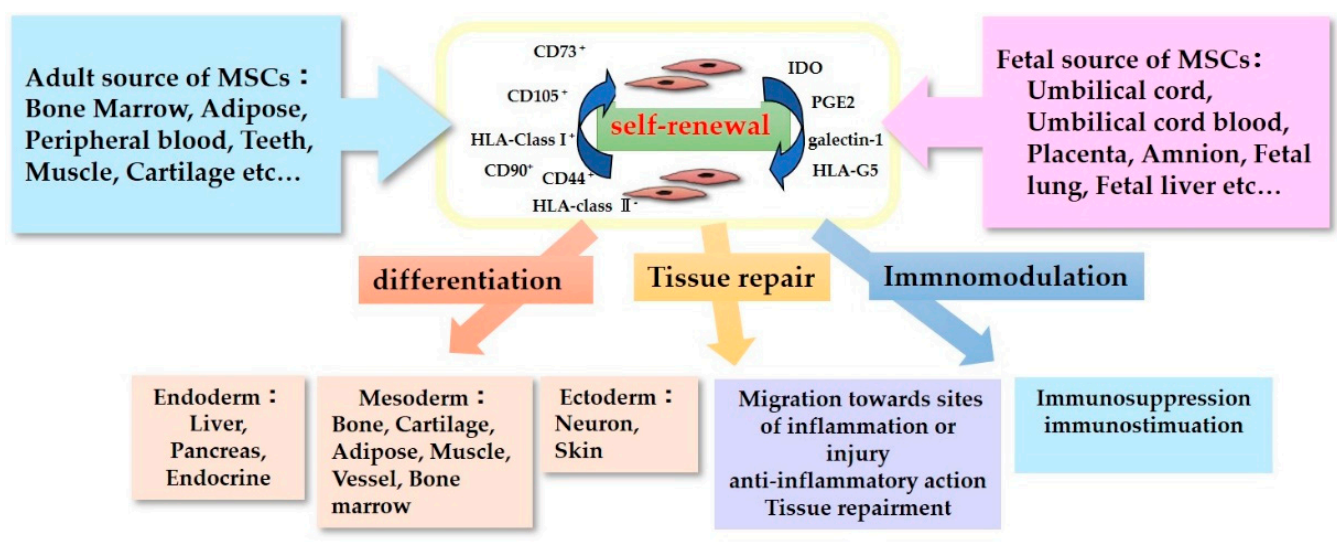

Figure 1. Characteristics of Mesenchymal stromal/stem cells (MSCs).

In this review, we discuss the effects demonstrated by MSCs in neurological injury models and their mechanisms. We also summarize the recent progress in regenerative therapies using MSCs for the potential treatment of various neurological disorders.

\section{Mechanisms of ACTION of MSC on Neurological Injury Models}

MSCs have been reported to secrete heterogeneous lipid bilayer vesicles called extracellular vesicles (EVs), which act as mediators for inter-cell communication [17]. These exosomes/EVs secreted from MSCs are known to improve neuronal functions in neurological injured models $[17,18]$. We have also demonstrated the amelioration of neuronal injury followed by functional improvement in MSC-administered mice models, which resulted from the secretion of trophic factors rather than neuronal differentiation and eternal cell replacement by MSCs [15]. In addition, immunomodulatory effects lacking HLA-class II expression and secreting IDO, PGE2, galectin-1, and HLA-G5 are the most important property of MSCs in their clinical use. Therefore, MSCs could be useful therapeutics for neurological disorders accompanying inflammation.

Regarding the way of administration of MSCs, most studies adopt intravenous injection (IV) or intrathecal injection (IT). On the other hand, there are some notable basic research studies reporting the efficacy of MSCs by intranasal administration [19] and either stereotaxically into the striatum or intra-arterially administration through the internal carotid artery [20]. Furthermore, Leong et al. investigated three different methods: direct stereotaxic injection into the lateral cerebral ventricle, intra-carotid administration, and femoral venous infusion, and of the three different methods of MSC transplantation tested in the present study, direct stereotaxic injection induced the highest concentration of MSCs in brain areas, resulting in the best neurological outcome [21].

EVs of MSCs have been reported to promote neurite development in middle cerebral artery (MCA) stroke models [22]. Moreover, MSC-EVs significantly upregulated p-AMPK and downregulated p-JAK2, p-STAT3, and p-NF- $\mathrm{B}$, which resulted in improvements in pathological lesions in cortical brain tissue and the attenuation of neuronal apoptosis in the cortex of an MCA occlusion rat model [23]. In addition, anti-inflammatory and immunomodulatory effects of MSC-derived exosomes are reported to be exerted by miR-30d inhibiting autophagy-mediated microglial polarization to M1 [24]. On the other hand, the efficacy of dental pulp stem cells (DPSCs) for focal cerebral ischemia has been reported [25]. 
They demonstrated that treatment with DPSCs combined with BDNF promoted the recovery of neurological function more effectively compared with BDNF injection or DPSC transplantation alone. Furthermore, Wu et al. reported that periodontal ligament stem cells (PDLSCs) transplantation promoted the recovery of neurological function more effectively than DPSC transplantation in rats with transient occlusion of the right middle cerebral artery [26].

MSCs have also shown potential in the healing of spinal cord injury (SCI) in a rat model through inhibition of pericyte migration. This improved motor functioning and the structural integrity of the blood-spinal cord barrier [27]. Treatment with BM-MSC derived exosome have been reported to reduce neuronal cell death, improve myelin arrangement and reduce myelin loss, increase pericyte/endothelial cell coverage on the vascular wall, decrease blood-spinal cord barrier leakage, reduce caspase 1 expression, inhibit interleukin$1 \beta$ release, and accelerate locomotor functional recovery in rats with SCI [28]. Moreover, Li et al. demonstrated the inhibition of neuronal apoptosis via activation of the Wnt/betacatenin signaling pathway by MSCs in an SCI model [29].

Furthermore, hypoxic ischemic (HI) models have often been used as a mimic model of cerebral palsy. Sisa et al. reported that EVs from MSCs could exert a neuroprotective effect in mouse models with severe HI-induced neonatal brain injury [30]. Thomi et al. reported that exosomes from UC-MSCs also reached the brain and reduced microgliamediated neuroinflammation in rats with perinatal brain injury [31]. MSC treatment is also reported to ameliorate inflammation-induced neuronal cellular degeneration, reduce microgliosis, and prevent reactive astrogliosis, resulting in improved long-lasting cognitive functions [32].

Regarding amyotrophic lateral sclerosis (ALS), the repeated administration of ADMSC exosomes was reported to improve the motor performance; protect lumbar motoneurons, the neuromuscular junction, and muscles; and decrease the activation of glial cells in ALS model mice [33]. Corti et al. reported that BM-MSCs promoted the survival of motor neurons and improved neuromuscular function in SOD1 G93A mice, leading to prolonged disease duration and lifespan [34]. Moreover, they showed transplanted cells were engrafted within the host spinal cord. Consistently, the intravenous administration of AD-MSCs in superoxide-dismutase 1 (SOD1)-mutant transgenic mice was able to promote neuroprotective and neuroregenerative actions [35]. They also showed the migration of AD-MSCs in the anterior horn of the spinal cord, though they did not show neuronal or glial markers.

As for multiple sclerosis (MS), in vitro data demonstrated that MSC-secreted EVs promote myelin regeneration by inducing the differentiation of endogenous oligodendrocyte precursor cells into mature myelinating oligodendrocytes [36]. On the other hand, Riazifar et al. found that the intravenous administration of MSCs-EV stimulated by IFN $\gamma$ reduced the mean clinical score of encephalomyelitis mice compared to PBS control, reduced demyelination, decreased neuroinflammation, and upregulated the number of CD4+CD25+FOXP3+ regulatory T cells (Tregs) within the spinal cords of encephalomyelitis mice [37].

Parkinson's disease is a common neurodegenerative disorder, and effective treatments are not available at the present. Choi et al. reported that the intravenous administration of AD-MSCs significantly improved the behavioral performances at 3 weeks after the injection of MSCs in the Parkinson's disease mouse model induced by 6-hydroxydopamine. Additionally, dopaminergic neurons were rescued, the number of structure-modified mitochondria was decreased, and the mitochondrial complex I activity was restored in the brains of the AD-MSCs injected mouse, which suggests that AD-MSCs may have therapeutic potential for Parkinson's disease by recovering mitochondrial functions [38]. On the other hand, a Rotenone-induced rat model is also used for Parkinson's disease mouse model. The intravenous administration of BM-MSCs was able to migrate to the injured brain, and they significantly decreased serum TGF- $\beta 1$ levels and increased levels of serum BDNF and brain dopamine [39]. 
There are also some reports showing the efficacy of MSCs for traumatic brain injury models. Compared with the vehicle, human BM-MSCs exosome treatment significantly improved sensorimotor and cognitive function, reduced hippocampal neuronal cell loss, promoted angiogenesis and neurogenesis, and reduced neuroinflammation in a traumatic brain injury model [40]. On the other hand, $\mathrm{Xu}$ et al. reported that the BDNF-mediated MSCs exosome promotes neurogenesis and inhibits apoptosis in traumatic brain injury model rats [41].

Alzheimer's disease, which is the most common type of dementia, is characterized by the degeneration and death of neurons in the basal forebrain, hippocampus, and cerebral cortex. Some reports demonstrate the efficacy of MSCs for the transgenic APP/PS1 mouse model, which is a mimic of Alzheimer's disease. Positive effects have been reported by delivering BM-MSCs into the lateral ventricles of a transgenic APP/PS1/tau mouse model. Better preservation of working memory and downregulation of potentially toxic $A \beta * 56$ levels in the entorhinal cortex have been described [42]. On the other hand, Routajangout et al. used UC-MSCs for APP/PS1 mouse by intracarotid injections. They reported a reduction of the cognitive loss and reduction of $A \beta$ deposits in the cerebral cortex and the hippocampus [43].

There are also many basic research studies that investigate the efficacy of MSCs for Huntington's disease, which is characterized by progressive neuronal cell death, resulting in cognitive decline, involuntary choreic movements, and psychiatric disturbances. Dey et al. evaluated the therapeutic effects of the transplantation of BM-MSCs genetically engineered to over-express BDNF or NGF on motor deficits and neurodegeneration in YAC 128 transgenic mice [44]. They demonstrated that YAC 128 mice that were transplanted with MSCs over-expressing BDNF had the longest latencies on the rotarod and the least amount of neuronal loss within the striatum of the YAC 128 mice. In addition, striatal injection of BM-MSCs engineered to overexpress BDNF has been reported to decrease striatal atrophy and reduce anxiety in YAC128 mice [45]. These genetically modified MSCs could potentially be a stem cell-based neurotherapeutics for neurodegenerative disorders.

\section{Clinical Application of MSCs for Neurological Disorders}

Based on the mechanisms suggested by the basic experiments mentioned above, several clinical trials using MSCs for neurological disorders have been conducted, and the recent clinical reports are summarized in this review.

Most of these clinical studies were performed with adult participants, while trials focusing on cerebral palsy were performed with children. Regarding the origin of MSCs; $\mathrm{BM}, \mathrm{UC}, \mathrm{UCB}$, and AD sources have all been used. In addition, DPSC s are used for clinical trials for neurological disorders [46,47]. As for the administration of MSCs, most clinical studies adopt IV and/or IT. These clinical trials have mainly reported on the feasibility and efficacy of MSC therapies for neurological disorders, with some reporting adverse events, such as fever, vomiting, and headaches, while severe adverse events have not been observed.

\subsection{Ischemic Stroke}

The recent clinical reports using MSCs for the treatment of ischemic stroke are summarized in Table 1. Some studies have reported on the safety and feasibility of BM-MSCs in patients with ischemic stroke injury [48-51]. In these clinical trials, patients received intravenous injections of BM-MSCs, and an improvement in neurological functioning was observed, while no treatment-related adverse events were seen. Qiao et al. highlighted the safety and feasibility of the co-transplantation of neural stem/progenitor cells (NSPCs) and UC-MSCs in patients who had suffered from an ischemic stroke [52]. In the study, no tumorigenesis was found during a two-year follow-up, and the neurological functions, disability levels, and daily living abilities of the patients had improved. Jiang et al. reported on the safety and efficacy of UC-MSCs delivered via a catheter to a near-lesion site for treating an infarction in the middle cerebral artery territory [53]. UC-MSCs were infused 
via catheterization in the M1 segment of the middle cerebral artery. Cell delivery was performed successfully in all the patients, and no major accidents were observed. After this cellular therapy, two of the three ischemic stroke patients demonstrated improved muscle strength. These reports suggest that the transplantation of MSCs in subjects with ischemic stroke is safe and may promote neurological improvement. On the other hand, Nagpal et al. conducted a clinical trial using DPSC for stroke called TOOTH (The Open study of dental pulp stem cell Therapy in Humans) and are investigating the use of autologous stem cell therapy for stroke survivors with chronic disability [47].

Table 1. Summary of recent clinical trials using MSCs for ischemic stroke.

\begin{tabular}{|c|c|c|c|c|c|c|c|c|c|c|}
\hline \multirow{2}{*}{ Reference } & \multirow{2}{*}{ Disease } & \multirow{2}{*}{ Source } & \multicolumn{2}{|c|}{ Number } & \multirow{2}{*}{$\begin{array}{l}\text { Mean Age } \\
\text { (Range), Year }\end{array}$} & \multirow{2}{*}{$\begin{array}{c}\text { Route of } \\
\text { Administration }\end{array}$} & \multirow{2}{*}{ Number of Cells } & \multirow{2}{*}{$\begin{array}{l}\text { Number of } \\
\text { Treatments }\end{array}$} & \multirow{2}{*}{ Results } & \multirow{2}{*}{$\begin{array}{c}\text { Adverse } \\
\text { Events }\end{array}$} \\
\hline & & & Trial & Control & & & & & & \\
\hline Chung et al. [48] & $\begin{array}{l}\text { Ischemic } \\
\text { stroke } \\
\text { (Phase 3) }\end{array}$ & BM & 39 & 15 & $\begin{array}{c}68 \\
(28-83)\end{array}$ & IV & $1 \times 10^{6} / \mathrm{kg}$ & 1 & $\begin{array}{l}\text { Lower extremity } \\
\text { motor functional } \\
\text { recovery after } \\
3 \text { months }\end{array}$ & No \\
\hline Bhasin et al. [49] & $\begin{array}{l}\text { Ischemic } \\
\text { stroke }\end{array}$ & BM & 6 & 6 & $\begin{array}{c}42.8 \\
(20-60)\end{array}$ & IV & $5-6 \times 10^{7}$ cells & 1 & $\begin{array}{l}\text { Improvement in } \\
\text { the activities of } \\
\text { daily living } \\
\text { (ADL) after } 156 \\
\text { and } 208 \text { weeks }\end{array}$ & No \\
\hline Qiao et al. [52] & $\begin{array}{l}\text { Ischemic } \\
\text { stroke } \\
\text { (Phase 1/2) }\end{array}$ & UC & 6 & 0 & $\begin{array}{l}56.17 \\
(3-85)\end{array}$ & IVIV + IC & $\begin{array}{c}\text { IV:MSC } \\
0.5 \times 10^{6} / \mathrm{kg} \\
\text { IC:MSC } \\
5 \times 10^{6} \text { cells } \\
\text { NSPC } \\
6 \times 10^{6} \text { cells } \\
\text { at one-week } \\
\text { interval }\end{array}$ & $\begin{array}{c}4 \\
\text { or } \\
1+3\end{array}$ & $\begin{array}{l}\text { Improvement in } \\
\text { the neurological } \\
\text { functions and } \\
\text { ADL after } 3,12, \\
24 \text { months }\end{array}$ & $\begin{array}{c}\text { Fever, } \\
\text { dizziness }\end{array}$ \\
\hline Jiang et al. [53] & $\begin{array}{l}\text { Ischemic and } \\
\text { hemorrhagic } \\
\text { stroke }\end{array}$ & UC & 4 & 0 & $40-59$ & $\begin{array}{c}\text { IA (intra- } \\
\text { arterial) via } \\
\text { catheterization }\end{array}$ & $2 \times 10^{7}$ cells & 1 & $\begin{array}{l}\text { Motor functional } \\
\text { recovery and } \\
\text { improvement in } \\
\text { the ADL after } 3 \\
\text { and } 6 \text { months }\end{array}$ & No \\
\hline Bhasin et al. [50] & $\begin{array}{l}\text { Ischemic } \\
\text { stroke }\end{array}$ & $\mathrm{BM}$ & $\begin{array}{c}20 \\
\text { MSC6 } \\
\text { MNC14 }\end{array}$ & 20 & 45.1 & IV & $5-6 \times 10^{7}$ cells & 1 & $\begin{array}{l}\text { Improvement } \\
\text { in the ADL } \\
\text { after } 8 \text { and } \\
24 \text { weeks }\end{array}$ & No \\
\hline Honmou et al. [51] & $\begin{array}{l}\text { Ischemic } \\
\text { stroke } \\
\text { (Phase 1) }\end{array}$ & BM & 12 & 0 & $\begin{array}{c}59.2 \\
(41-73)\end{array}$ & IV & $0.6-1.8 \times 10^{8}$ cells & 1 & $\begin{array}{l}\text { Incremental } \\
\text { daily rate of } \\
\text { change in the } \\
\text { disability scales } \\
\text { during } 12 \text { months }\end{array}$ & $\begin{array}{l}\text { Fever, } \\
\text { nausea, } \\
\text { itching }\end{array}$ \\
\hline
\end{tabular}

IV, intravenous injection; IT, intrathecal injection; IC, intracranial; BM, bone marrow; UC, umbilical cord.

\subsection{Spinal Cord Injury}

In most of the clinical trials involving MSC treatment for spinal cord injury (SCI), MSCs were administered via intrathecal or direct infusion to the injured lesion (Table 2). Vaquero et al. reported that patients administered BM-MSCs showed variable clinical improvements in sensitivity, motor power, spasms, spasticity, neuropathic pain, sexual function, and/or sphincter dysfunction, regardless of the level/degree of injury, age, or time elapsed since the SCI [54]. Hur showed the effects and safety of the intrathecal transplantation of autologous AD-MSCs in patients with SCI. Over the 8 months of followup, patients who received intrathecal transplantation of autologous AD-MSCs for SCI treatment did not experience any serious adverse events, and several patients showed mild improvements in neurological function [55]. Transplanting collagen scaffolds with human UC-MSCs has also been reported to have therapeutic potential as a treatment for SCI. Collagen scaffolds with human UC-MSCs were transplanted into the injury site directly, and the recovery of sensory and motor functions was observed in both patients [56]. Oh et al. reported on the injection of autologous BM-MSCs into the intramedullary area and subdural space and concluded that this single MSCs application was safe, but it had a very weak therapeutic effect compared with multiple MSC injections [57]. Therefore, further clinical trials to enhance the effect of MSCs are necessary in the future. 
Table 2. Summary of recent clinical trials using MSCs for SCI.

\begin{tabular}{|c|c|c|c|c|c|c|c|c|c|c|}
\hline \multirow{2}{*}{ Reference } & \multirow{2}{*}{ Disease } & \multirow{2}{*}{ Source } & \multicolumn{2}{|c|}{ Number } & \multirow{2}{*}{$\begin{array}{l}\text { Mean Age } \\
\text { (Range), Year }\end{array}$} & \multirow{2}{*}{$\begin{array}{c}\text { Route of } \\
\text { Administration }\end{array}$} & \multirow{2}{*}{$\begin{array}{l}\text { Number } \\
\text { of Cells }\end{array}$} & \multirow{2}{*}{$\begin{array}{l}\text { Number of } \\
\text { Treatments }\end{array}$} & \multirow{2}{*}{ Results } & \multirow{2}{*}{$\begin{array}{l}\text { Adverse } \\
\text { Events }\end{array}$} \\
\hline & & & Trial & Control & & & & & & \\
\hline Xiao et al. [56] & $\begin{array}{l}\text { Spinal cord } \\
\text { injury } \\
\text { (Phase 1) }\end{array}$ & UCB & 2 & 0 & 28,30 & $\begin{array}{l}\text { Transplantation } \\
\text { into the lesion } \\
\text { with collagen } \\
\text { scaffolds }\end{array}$ & $4 \times 10^{7}$ cells & 1 & $\begin{array}{l}\text { Motor functional } \\
\text { recovery after } 3 \text {, } \\
6,12 \text { months } \\
\text { Sensory functional } \\
\text { recovery after } 2 \\
4,12 \text { months }\end{array}$ & No \\
\hline Vaquero et al. [54] & $\begin{array}{l}\text { Spinal cord } \\
\text { injury } \\
\text { (Phase 2) }\end{array}$ & $\mathrm{BM}$ & 11 & 0 & $\begin{array}{c}44.91 \\
(28-62)\end{array}$ & IT & $\begin{array}{l}100 \times 10^{6} \text { cells } \\
\text { at } 3 \text { months } \\
\text { interval }\end{array}$ & 3 & $\begin{array}{l}\text { Motor, sensory and } \\
\text { bladder-bowel } \\
\text { functional recovery } \\
\text { after } 4,7,10 \text { months }\end{array}$ & No \\
\hline Vaquero et al. [58] & $\begin{array}{l}\text { Post-traumatic } \\
\text { syringomyelia } \\
\text { (Phase 2) }\end{array}$ & BM & 6 & 0 & $\begin{array}{c}39 \\
(30-50)\end{array}$ & $\begin{array}{l}\text { Direct injection } \\
\text { into the lesion }\end{array}$ & $300 \times 10^{6}$ cells & 1 & $\begin{array}{c}\text { Achieving } \\
\text { reduction of syrinx } \\
\text { and valiable clinical } \\
\text { improvements } \\
\text { after } 6 \text { months }\end{array}$ & No \\
\hline Vaquero et al. [59] & $\begin{array}{l}\text { Spinal cord } \\
\text { injury } \\
\text { (Phase 2) }\end{array}$ & $\mathrm{BM}$ & 10 & 0 & $\begin{array}{c}42.2 \\
(34-59)\end{array}$ & IT & $\begin{array}{c}30 \times 10^{6} \text { cells at } \\
\text { 3-months } \\
\text { interval }\end{array}$ & 4 & $\begin{array}{l}\text { Motor, sensory and } \\
\text { bladder-bowel } \\
\text { functional recovery } \\
\text { after } 3,6,9 \\
12 \text { months }\end{array}$ & $\begin{array}{l}\text { Headache, } \\
\text { puncture } \\
\text { pain }\end{array}$ \\
\hline Satti et al. [60] & $\begin{array}{l}\text { Spinal cord } \\
\text { injury } \\
\text { (Phase 1) }\end{array}$ & BM & 9 & 0 & $\begin{array}{c}31.6 \\
(24-38)\end{array}$ & IT & $\begin{array}{l}1.2 \times 10^{6} / \mathrm{kg} \text { at } \\
4 \text { weeks interval }\end{array}$ & 2 or 3 & $\begin{array}{l}\text { Only safety } \\
\text { assessment }\end{array}$ & No \\
\hline Oh et al. [57] & $\begin{array}{l}\text { Spinal cord } \\
\text { injury } \\
\text { (Phase 3) }\end{array}$ & $\mathrm{BM}$ & 16 & 0 & $\begin{array}{c}40.9 \\
(18-65)\end{array}$ & $\begin{array}{l}\text { Direct injection } \\
\text { into the lesion + IT }\end{array}$ & $\begin{array}{l}1.6 \times 10^{7} \text { cells } \\
3.2 \times 10^{7} \text { cells }\end{array}$ & 1 & $\begin{array}{c}\text { Very weak } \\
\text { therapeutic } \\
\text { efficacy after } \\
6 \text { months }\end{array}$ & $\begin{array}{l}\text { Sensory } \\
\text { deterioration, } \\
\text { muscle } \\
\text { rigidity, } \\
\text { tingling sense }\end{array}$ \\
\hline Hur et al. [55] & $\begin{array}{l}\text { Spinal cord } \\
\text { injury } \\
\text { (Phase 1) }\end{array}$ & $\mathrm{AD}$ & 14 & 0 & $\begin{array}{c}41.9 \\
(20-66)\end{array}$ & IT & $\begin{array}{c}3 \times 10^{7} \text { at } \\
\text { 1-month interval }\end{array}$ & 3 & $\begin{array}{l}\text { Motor and sensory } \\
\text { functional recovery } \\
\text { after } 8 \text { months }\end{array}$ & $\begin{array}{l}\text { Nausea, } \\
\text { vomit, } \\
\text { headache }\end{array}$ \\
\hline Mendonça et al. [61] & $\begin{array}{l}\text { Spinal cord } \\
\text { injury } \\
\text { (Phase 1) }\end{array}$ & $\mathrm{BM}$ & 14 & 0 & $\begin{array}{c}35.7 \\
(23-61)\end{array}$ & $\begin{array}{l}\text { Direct injection } \\
\text { into the lesion }\end{array}$ & $\begin{array}{c}5 \times 10^{6} \text { cells } / \mathrm{cm}^{3} \\
\text { per lesion } \\
\text { volume }\end{array}$ & 1 & $\begin{array}{l}\text { Motor, sensory, and } \\
\text { bladder-bowel } \\
\text { functional recovery } \\
\text { after } 6 \text { months }\end{array}$ & $\begin{array}{l}\text { Low-intensity } \\
\text { pain at the } \\
\text { incision site, } \\
\text { cerebrospinal } \\
\text { fluid leak }\end{array}$ \\
\hline Cheng et al. [62] & $\begin{array}{l}\text { Spinal cord } \\
\text { injury } \\
\text { (Phase 2) }\end{array}$ & UC & 10 & 34 & $\begin{array}{c}35.3 \\
(19-57)\end{array}$ & $\begin{array}{l}\text { Direct injection } \\
\text { into the lesion }\end{array}$ & $\begin{array}{l}2 \times 10^{7} \text { cells at } \\
10 \text { days interval }\end{array}$ & 2 & $\begin{array}{l}\text { Motor, sensory, } \\
\text { and bladder } \\
\text { functional recovery } \\
\text { after } 6 \text { months } \\
\text { Superior efficacy } \\
\text { than that of } \\
\text { rehabilitation } \\
\text { therapy }\end{array}$ & $\begin{array}{l}\text { Radiating } \\
\text { neuralgia }\end{array}$ \\
\hline Dai et al. [63] & $\begin{array}{l}\text { Spinal cord } \\
\text { injury } \\
\text { (Phase 1/2) }\end{array}$ & $\mathrm{BM}$ & 20 & 20 & $22-54$ & $\begin{array}{l}\text { Direct injection } \\
\text { into the lesion }\end{array}$ & $20 \times 10^{6}$ cells & 1 & $\begin{array}{l}\text { Motor, sensory, } \\
\text { and bladder } \\
\text { functional recovery } \\
\text { after } 6 \text { months }\end{array}$ & $\begin{array}{l}\text { Fever, } \\
\text { headache, } \\
\text { pain }\end{array}$ \\
\hline Karamouzian et al. [64] & $\begin{array}{l}\text { Spinal cord } \\
\text { injury } \\
\text { (Phase 1/2) }\end{array}$ & BM & 11 & 20 & $\begin{array}{c}33.2 \\
(23-48)\end{array}$ & IT & $0.7-1.2 \times 10^{6}$ cells & 1 & $\begin{array}{l}\text { Possible efficacy } \\
\text { in the motor and } \\
\text { sensory function }\end{array}$ & No \\
\hline
\end{tabular}

$\mathrm{IT}$, intrathecal injection; $\mathrm{BM}$, bone marrow; $\mathrm{AD}$, adipose; $\mathrm{UC}$, umbilical cord; $\mathrm{UCB}$, umbilical cord blood.

\subsection{Cerebral Palsy}

Recently, MSCs have been emerging for use in potential new therapeutic treatments for children with cerebral palsy. The recent clinical reports using MSCs for the treatment of cerebral palsy are summarized in Table 3. Huang et al. reported on a randomized, placebo-controlled trial of UCB-MSC infusion in children with cerebral palsy [65]. The infusion group was comprised of 27 patients, each of whom received four infusions of UCB-MSCs and basic rehabilitation treatment, whereas another 27 patients were assigned to the control group and received $0.9 \%$ normal saline and basic rehabilitation treatment. The changes in the gross motor and comprehensive functional scale in the UCB-MSC infusion group were significantly higher than those in control group at 3-, 6-, 12-, and 24-months post treatment. Liu et al. investigated whether BM-MSCs and BM-mononuclear cells (BM-MNCs) had any difference in curative effect regarding their use in the treatment of cerebral palsy. Their results indicated that BM-MSC transplantation for the treatment of cerebral palsy is safe and can improve gross and fine motor function significantly when compared with the results of BM-MNC treatment [66]. Cerebral palsy and its associated conditions can cause significant economic burdens to families. Therefore, clinical trials that may lead to new cell therapy strategies should be further investigated. 
Table 3. Summary of recent clinical trials using MSCs for cerebral palsy.

\begin{tabular}{|c|c|c|c|c|c|c|c|c|c|c|}
\hline \multirow{2}{*}{ Reference } & \multirow{2}{*}{ Disease } & \multirow{2}{*}{ Source } & \multicolumn{2}{|c|}{ Number } & \multirow{2}{*}{$\begin{array}{l}\text { Mean Age } \\
\text { (Range), Year }\end{array}$} & \multirow{2}{*}{$\begin{array}{c}\text { Route of } \\
\text { Administration }\end{array}$} & \multirow{2}{*}{ Number of Cells } & \multirow{2}{*}{$\begin{array}{l}\text { Number of } \\
\text { Treatments }\end{array}$} & \multirow{2}{*}{ Results } & \multirow{2}{*}{$\begin{array}{l}\text { Adverse } \\
\text { Events }\end{array}$} \\
\hline & & & Trial & Control & & & & & & \\
\hline Gu et al. [67] & $\begin{array}{c}\text { Cerebral } \\
\text { palsy } \\
\text { (Phase 1/2) }\end{array}$ & UC & 19 & 20 & 4.29 & IV & $\begin{array}{l}4.5-5.5 \times 10^{7} \text { cells } \\
\text { at } 7 \text {-day intervals }\end{array}$ & 4 & $\begin{array}{l}\text { Gross motor and } \\
\text { comprehensive } \\
\text { functional recovery } \\
\text { and improvement in } \\
\text { the ADL after } 3,6 \text {, } \\
12 \text { months }\end{array}$ & No \\
\hline Ahn et al. [68] & $\begin{array}{l}\text { Intraventricular } \\
\text { hemorrhage } \\
\text { (Phase 1) }\end{array}$ & $\mathrm{UCB}$ & 9 & 0 & $\begin{array}{l}11.6 \\
(7-15) \\
\text { (days) }\end{array}$ & Intraventricular & $\begin{array}{l}5 \times 10^{6} / \mathrm{kg} \\
\text { or } \\
1 \times 10^{7} / \mathrm{kg}\end{array}$ & 1 & $\begin{array}{l}\text { Only safety } \\
\text { assessment }\end{array}$ & No \\
\hline Huang et al. [65] & $\begin{array}{c}\text { Cerebral } \\
\text { palsy } \\
\text { (Phase 1/2) }\end{array}$ & UCB & 27 & 27 & $\begin{array}{c}7.4 \\
(3-12)\end{array}$ & IV & $\begin{array}{l}5 \times 10^{7} \text { cells at } \\
7 \text {-day intervals }\end{array}$ & 4 & $\begin{array}{l}\text { Gross motor and } \\
\text { comprehensive } \\
\text { functional recovery } \\
\text { after } 3,6,12 \\
24 \text { months }\end{array}$ & No \\
\hline Liu et al. [66] & $\begin{array}{c}\text { Cerebral } \\
\text { palsy } \\
\text { (Phase 1/2) }\end{array}$ & $\mathrm{BM}$ & $\begin{array}{l}\text { MSC } 33 \\
\text { MNC34 }\end{array}$ & 35 & $\begin{array}{c}7-132 \\
\text { (months) }\end{array}$ & IT & $\begin{array}{c}1 \times 10^{6} / \mathrm{kg} \text { at } \\
3 \text {-4-day intervals }\end{array}$ & 4 & $\begin{array}{l}\text { Motor functional } \\
\text { recovery after } \\
12 \text { months }\end{array}$ & No \\
\hline Wang et al. [69] & $\begin{array}{c}\text { Cerebral } \\
\text { palsy } \\
\text { (Phase 4) }\end{array}$ & UC & $\begin{array}{c}16 \\
\text { (8 twins) }\end{array}$ & 0 & $\begin{array}{c}6.29 \\
(3-12)\end{array}$ & IT & $\begin{array}{l}1-2 \times 10^{6} \text { cells at } \\
3-5 \text {-day intervals }\end{array}$ & 4 & $\begin{array}{l}\text { Motor functional } \\
\text { recovery after } 1 \\
\text { and } 6 \text { months }\end{array}$ & No \\
\hline Wang X et al. [70] & $\begin{array}{l}\text { Cerebral } \\
\text { palsy }\end{array}$ & $\mathrm{BM}$ & 46 & 0 & $\begin{array}{c}\text { 6-180 } \\
\text { (months) }\end{array}$ & $\begin{array}{c}\text { IT } \\
\text { Intra-Parenchymal }\end{array}$ & $\begin{array}{l}2 \times 10^{7} \text { cells } \\
4 \times 10^{7} \text { cells } \\
\text { at } 5 \text {-day intervals }\end{array}$ & $\begin{array}{l}2+1 \\
\text { or } 4\end{array}$ & $\begin{array}{l}\text { Gross motor } \\
\text { functional recovery } \\
\text { after } 1,6,18 \text { months }\end{array}$ & No \\
\hline
\end{tabular}

IV, intravenous injection; IT, intrathecal injection; BM, bone marrow; UC, umbilical cord; UCB, umbilical cord blood.

\subsection{Amyotrophic Lateral Sclerosis (ALS)}

ALS is a fatal neurodegenerative disease characterized by the degeneration of motor neurons in the brain and spinal cord, resulting in progressive muscle weakness and respiratory failure. The recent clinical reports using MSCs for the treatment of ALS are summarized in Table 4. Berry et al. highlighted the safety and efficacy of neurotrophic factor (NTF)-secreting MSCs (NurOwn ${ }^{\circledR}$, autologous bone marrow-derived MSCs, induced to secrete NTFs) delivered by combined intrathecal and intramuscular administration to participants with ALS in a phase 2 randomized controlled trial [71]. The rate of disease progression (Revised ALS Functional Rating Scale (ALSFRS-R) slope change) in the overall study population was similar in the treated and placebo participants, while in a prespecified rapid progressor subgroup, the rate of disease progression improved at early time points. Furthermore, CSF neurotrophic factors increased, and associated inflammatory biomarker levels decreased in the treated participants post-NTF-secreting MSC transplantation. Another report showed that intrathecal and intramuscular administration of BM-MSC secreting neurotrophic factors in patients with ALS is safe and may provide clinical benefits [72]. Syková et al. demonstrated that the intrathecal application of BM-MSCs in ALS patients is a safe procedure and that this treatment could slow down the progression of the disease; a reduction in ALSFRS decline at three months after application was observed which, in some cases, persisted for six months [73]. Oh et al. reported that two repeated intrathecal injections of autologous BM-MSCs was a safe and feasible treatment for ALS patients throughout the duration of a 12-month follow-up period [74]. These results support the possibility that the use of MSCs in ALS patients could slow down the progression of the disease. 
Table 4. Summary of recent clinical trials using MSCs for ALS.

\begin{tabular}{|c|c|c|c|c|c|c|c|c|c|c|}
\hline \multirow{2}{*}{ Reference } & \multirow{2}{*}{ Disease } & \multirow{2}{*}{ Source } & \multicolumn{2}{|c|}{ Number } & \multirow{2}{*}{$\begin{array}{l}\text { Mean Age } \\
\text { (Range), Year }\end{array}$} & \multirow{2}{*}{$\begin{array}{c}\text { Route of } \\
\text { Administration }\end{array}$} & \multirow{2}{*}{ Number of Cells } & \multirow{2}{*}{$\begin{array}{l}\text { Number of } \\
\text { Treatments }\end{array}$} & \multirow{2}{*}{ Results } & \multirow{2}{*}{ Adverse Events } \\
\hline & & & Trial & Control & & & & & & \\
\hline Berry et al. [71] & $\begin{array}{c}\text { ALS } \\
\text { (Phase 2) }\end{array}$ & BM-NTF & 36 & 12 & $\begin{array}{c}51.1 \\
(26-71)\end{array}$ & $\mathrm{IM}+\mathrm{IT}$ & $\begin{array}{l}\text { IM: } 48 \times 10^{6} \text { cells } \\
\text { IT: } 125 \times 10^{6} \text { cells }\end{array}$ & 1 & $\begin{array}{l}\text { Improvement in } \\
\text { the rate of disease } \\
\text { progression after } \\
6 \text { months }\end{array}$ & $\begin{array}{l}\text { Headache, } \\
\text { fever, back pain, } \\
\text { injection site } \\
\text { bruising }\end{array}$ \\
\hline Syková et al. [73] & $\begin{array}{c}\text { ALS } \\
\text { (Phase 1/2) }\end{array}$ & BM & 26 & 0 & $\begin{array}{c}51.2 \\
(33-64)\end{array}$ & IT & $15 \pm 4.5 \times 10^{6}$ cells & 1 & $\begin{array}{l}\text { Slowing down of the } \\
\text { diseaseprogression } \\
\text { after } 3,6,9 \text { months }\end{array}$ & Headache \\
\hline Staff et al. [75] & $\begin{array}{c}\text { ALS } \\
\text { (Phase 1) }\end{array}$ & $\mathrm{AD}$ & 27 & 0 & $36-75$ & IT & $\begin{array}{c}1 \times 10^{7}, 5 \times 10^{7} \\
5 \times 10^{7} \times 2 \\
1 \times 10^{8} \\
1 \times 10^{8} \times 2\end{array}$ & 1 or 2 & $\begin{array}{l}\text { Only safety } \\
\text { assessment }\end{array}$ & $\begin{array}{l}\text { Temporary back } \\
\text { and leg pain in } \\
\text { the highest dose }\end{array}$ \\
\hline Petrou et al. [72] & $\begin{array}{c}\text { ALS } \\
\text { (Phase 1/2) }\end{array}$ & BM-NTF & 26 & 0 & $\begin{array}{l}48.1,50.8 \\
(23-65)\end{array}$ & $\begin{array}{c}\mathrm{IM} \\
\text { IT } \\
\mathrm{IM}+\mathrm{IT}\end{array}$ & $\begin{array}{c}\mathrm{IM:} \\
2.4-4.8 \times 10^{7} \text { cells } \\
\mathrm{IT:} \\
1.0-2.0 \times 10^{6} / \mathrm{kg}\end{array}$ & 1 & $\begin{array}{l}\text { Improvement in } \\
\text { the rate of disease } \\
\text { progression after } \\
6 \text { months }\end{array}$ & $\begin{array}{l}\text { Fever, } \\
\text { vomiting, } \\
\text { headache }\end{array}$ \\
\hline Rushkevich et al. [76] & ALS & $\begin{array}{l}\text { BM-MSC } \\
\text { and neural } \\
\text { induced } \\
\text { MSC }\end{array}$ & 10 & 15 & $\begin{array}{c}54.5,55.0 \\
(37-66)\end{array}$ & $\mathrm{IV}+\mathrm{IT}$ & $\begin{array}{l}0.5-1.5 \times 10^{6} / \mathrm{kg} \\
5.0-9.7 \times 10^{6} \text { cells } \\
\text { at } 5-7 \text {-month } \\
\text { intervals }\end{array}$ & 1 or 2 & $\begin{array}{l}\text { Slowing down } \\
\text { of the disease } \\
\text { progression after } \\
12 \text { months }\end{array}$ & Fever, headache \\
\hline Oh et al. [74] & $\begin{array}{c}\text { ALS } \\
\text { (Phase 1) }\end{array}$ & BM & 8 & 0 & $\begin{array}{c}45.7 \\
(29-62)\end{array}$ & IT & $\begin{array}{c}1 \times 10^{6} / \mathrm{kg} \text { at } \\
26 \text {-day intervals }\end{array}$ & 2 & $\begin{array}{c}\text { No efficacy } \\
\text { after } 6 \text { months }\end{array}$ & $\begin{array}{l}\text { Fever, pain, } \\
\text { headache }\end{array}$ \\
\hline Kim et al. [77] & ALS & BM & 37 & 0 & $52.7,48.8$ & IT & $\begin{array}{c}1 \times 10^{6} / \mathrm{kg} \text { at } \\
\text { one-month } \\
\text { intervals }\end{array}$ & 2 & $\begin{array}{l}\text { Trophic factors } \\
\text { associated with a } \\
\text { positive response } \\
\text { to treat }\end{array}$ & No \\
\hline Mazzini et al. [78] & $\begin{array}{c}\text { ALS } \\
\text { (Phase 1) }\end{array}$ & BM & 19 & 0 & $20-75$ & $\begin{array}{l}\text { Direct } \\
\text { injection into } \\
\text { spinal cord }\end{array}$ & $7-152 \times 10^{6}$ cells & 1 & $\begin{array}{c}\text { No long-term } \\
\text { adverse effect after } \\
\text { nearly } 9 \text { years }\end{array}$ & No \\
\hline
\end{tabular}

IV, intravenous injection; IT, intrathecal injection; IM, intramuscular injection; BM, bone marrow; AD, adipose.

\subsection{Multiple Sclerosis}

Multiple sclerosis is a chronic immune-mediated inflammatory disease in which the immune system progressively destroys the myelin sheath in the central nervous system. This disease can last from a few months to many years. The recent clinical reports using MSCs for the treatment of multiple sclerosis are summarized in Table 5. Petrou et al. evaluated the optimal safe and effective clinical transplantation of MSCs in patients with active and progressive multiple sclerosis [79]. In the study, patients were randomized into three groups and treated intrathecally (IT) or intravenously (IV) with autologous BM-MSCs or sham injections. Significantly fewer patients experienced treatment failure in the MSC-IT and MSC-IV groups compared with those in the sham-treatment group. During the 1-year follow-up period, no evidence of disease activity was observed in $58.6 \%$ and $40.6 \%$ of patients treated with MSC-IT and MSC-IV, respectively, compared with $9.7 \%$ in the sham-treated group. MSC-IT transplantation induced additional benefits regarding the relapse rate, and the researchers concluded that the IT administration was more efficacious than the IV administration regarding several parameters of the disease. Furthermore, a safety and feasibility study was completed, focusing on the use of UC-MSCs for treating multiple sclerosis. Twenty subjects were enrolled in the study, and symptom improvements were most notable a month after treatment [80]. Infusion with MSCs is considered safe and feasible in patients with multiple sclerosis. However, larger studies investigating the number of doses and route of administration are needed to assess potential therapeutic benefits of this technique. 
Table 5. Summary of recent clinical trials using MSCs for multiple sclerosis.

\begin{tabular}{|c|c|c|c|c|c|c|c|c|c|c|}
\hline \multirow{2}{*}{ Reference } & \multirow{2}{*}{ Disease } & \multirow{2}{*}{ Source } & \multicolumn{2}{|c|}{ Number } & \multirow{2}{*}{$\begin{array}{l}\text { Mean Age } \\
\text { (Range), Year }\end{array}$} & \multirow{2}{*}{$\begin{array}{c}\text { Route of } \\
\text { Administration }\end{array}$} & \multirow{2}{*}{ Number of Cells } & \multirow{2}{*}{$\begin{array}{l}\text { Number of } \\
\text { Treatments }\end{array}$} & \multirow{2}{*}{ Results } & \multirow{2}{*}{$\begin{array}{l}\text { Adverse } \\
\text { Events }\end{array}$} \\
\hline & & & Trial & Control & & & & & & \\
\hline Petrou et al. [79] & $\begin{array}{l}\text { Multiple } \\
\text { sclerosis } \\
\text { (Phase 2) }\end{array}$ & BM & $\begin{array}{l}16 \\
16\end{array}$ & 16 & $\begin{array}{c}47.6 \\
(37.9-57.3)\end{array}$ & $\begin{array}{l}\text { IT } \\
\text { or } \\
\text { IV }\end{array}$ & $\begin{array}{c}1 \times 10^{6} / \mathrm{kg} \text { at } \\
6 \text {-month intervals }\end{array}$ & 1 or 2 & $\begin{array}{l}\text { Improvement in } \\
\text { the course of the } \\
\text { disease and } \\
\text { comprehensive } \\
\text { functional recovery } \\
\text { after } 3,6,12 \text { months. } \\
\text { IT is more } \\
\text { efficacious than IV }\end{array}$ & No \\
\hline Fernández et al. [81] & $\begin{array}{c}\text { Multiple } \\
\text { sclerosis } \\
\text { (phase 1/2) }\end{array}$ & $\mathrm{AD}$ & $\begin{array}{l}10, \\
9\end{array}$ & 11 & $\begin{array}{l}44.8 \\
47.8 \\
46.3\end{array}$ & IV & $\begin{array}{l}1 \times 10^{6} / \mathrm{kg} \\
\text { or } \\
4 \times 10^{6} / \mathrm{kg}\end{array}$ & 1 & $\begin{array}{l}\text { Partial efficacy } \\
\text { in the imaging } \\
\text { studies and } \\
\text { evoked potentials } \\
\text { after } 12 \text { months }\end{array}$ & $\begin{array}{l}\text { urinary } \\
\text { infection }\end{array}$ \\
\hline Riordan et al. [80] & $\begin{array}{c}\text { Multiple } \\
\text { sclerosis } \\
\text { (phase 1/2) }\end{array}$ & UC & 20 & 0 & 41.15 & IV & $\begin{array}{l}20 \times 10^{6} \text { cells at } \\
1-4 \text {-day intervals }\end{array}$ & 7 & $\begin{array}{l}\text { Comprehensive } \\
\text { functional recovery } \\
\text { after one month }\end{array}$ & $\begin{array}{l}\text { Headache, } \\
\text { fatigue }\end{array}$ \\
\hline Harris et al. [82] & $\begin{array}{l}\text { Multiple } \\
\text { sclerosis } \\
\text { (Phase 1) }\end{array}$ & $\begin{array}{c}\text { BM } \\
\text { MSC-derived } \\
\text { neural } \\
\text { progenitors }\end{array}$ & 20 & 0 & $27-65$ & IT & $\begin{array}{l}5.3-10 \times 10^{6} \text { cells } \\
\text { at 3-month } \\
\text { intervals }\end{array}$ & 3 & $\begin{array}{l}\text { Motor, bladder and } \\
\text { comprehensive } \\
\text { functional recovery } \\
\text { after } 3 \text { months }\end{array}$ & $\begin{array}{l}\text { headache, } \\
\text { fever }\end{array}$ \\
\hline Dahbour et al. [83] & $\begin{array}{l}\text { Multiple } \\
\text { sclerosis } \\
\text { (Phase 1/2) }\end{array}$ & $\begin{array}{c}\text { BM } \\
\text { MSC-CM }\end{array}$ & 10 & 0 & $\begin{array}{c}34.9 \\
(18-54)\end{array}$ & IT & $\begin{array}{l}\text { 93-168 } \times 10^{6} \text { cells } \\
\text { CM:13-20 mL at } \\
\text { 1-month intervals }\end{array}$ & $1+1$ & $\begin{array}{l}\text { Comprehensive } \\
\text { functional recovery } \\
\text { after } 12 \text { months }\end{array}$ & $\begin{array}{l}\text { Pain, } \\
\text { headache, } \\
\text { fever }\end{array}$ \\
\hline Llufriu et al. [84] & $\begin{array}{l}\text { Multiple } \\
\text { sclerosis } \\
\text { (Phase 2) }\end{array}$ & BM & 9 & 0 & $\begin{array}{c}36.8 \\
(23-48)\end{array}$ & IV & $1-2 \times 10^{6} / \mathrm{kg}$ & 1 & $\begin{array}{l}\text { Improvement in } \\
\text { the imaging } \\
\text { studies after } \\
6 \text { months }\end{array}$ & No \\
\hline Li et al. [85] & $\begin{array}{l}\text { Multiple } \\
\text { sclerosis }\end{array}$ & UC & 13 & 10 & $41.7,39.4$ & IV & $\begin{array}{c}4 \times 10^{6} \text { cells } / \mathrm{kg} \text { at } \\
2 \text {-week intervals }\end{array}$ & 3 & $\begin{array}{l}\text { Improvement in } \\
\text { the overall } \\
\text { symptoms and } \\
\text { fewer incidences } \\
\text { of relapse during } \\
12 \text { months }\end{array}$ & No \\
\hline Bonab et al. [86] & $\begin{array}{l}\text { Multiple } \\
\text { sclerosis } \\
\text { (Phase 2) }\end{array}$ & BM & 25 & 0 & $\begin{array}{c}34.7 \\
(23-50)\end{array}$ & IT & $2.95 \times 10^{7}$ cells & 1 & $\begin{array}{l}\text { Improvement or } \\
\text { stabilization } \\
\text { in the course of } \\
\text { the disease during } \\
12 \text { months }\end{array}$ & $\begin{array}{l}\text { Fever, nausea, } \\
\text { weakness in } \\
\text { the lower } \\
\text { limbs, } \\
\text { headache }\end{array}$ \\
\hline Lee et al. [87] & $\begin{array}{l}\text { Multiple } \\
\text { sclerosis } \\
\text { (Phase 2) }\end{array}$ & $\mathrm{BM}$ & 16 & 17 & $56.1,55.8$ & $\begin{array}{l}\text { IA (intra- } \\
\text { arterial) + IV }\end{array}$ & $\begin{array}{l}\text { IA: } 4 \times 10^{7} \text { cells } \\
\text { IV: } 4 \times 10^{7} \text { cells } \\
\text { at } 30 \text {-day intervals }\end{array}$ & $1+3$ & $\begin{array}{l}\text { Efficacy in } \\
\text { preventing the } \\
\text { progression of } \\
\text { neurological } \\
\text { deficits during } 12 \\
\text { months }\end{array}$ & $\begin{array}{l}\text { Small } \\
\text { ischemic } \\
\text { lesions }\end{array}$ \\
\hline Connick et al. [88] & $\begin{array}{l}\text { Multiple } \\
\text { sclerosis } \\
\text { (Phase 2) }\end{array}$ & BM & 10 & 0 & $\begin{array}{c}48.8 \\
(40-53)\end{array}$ & IV & $1.6 \times 10^{6} / \mathrm{kg}$ & 1 & $\begin{array}{l}\text { Visual functional } \\
\text { recovery after } \\
10 \text { months }\end{array}$ & $\begin{array}{l}\text { Macular rash, } \\
\text { self-limiting } \\
\text { infections }\end{array}$ \\
\hline
\end{tabular}

IV, intravenous injection; IT, intrathecal injection; BM, bone marrow; AD, adipose; UC, umbilical cord.

\subsection{Parkinson's Disease}

Parkinson's disease is the common and progressive neurodegenerative disease with major symptoms such as bradykinesia, impaired posture, and tremor. Some studies have reported on the safety and feasibility of MSCs in patients with Parkinson's disease (Table 6). Canesi et al. demonstrated the feasibility of BM-MSC in Parkinson's disease patients. One year after cell infusion, all treated patients were alive, except one, who died 9 months after the infusion for reasons not related to cell administration or to disease progression (accidental fall), and in all treated patients, motor function rating scales remained stable for at least six months during the one-year follow-up [89]. On the other hand, Carstens et al. showed the efficacy of AD-MSCs in two patients with Parkinson's disease. After the administration of AD-MSCs, subjective functional recovery after 2 weeks and up to 5 years are observed [90]. 
Table 6. Summary of recent clinical trials using MSCs for Parkinson's disease.

\begin{tabular}{|c|c|c|c|c|c|c|c|c|c|c|}
\hline \multirow{2}{*}{ Reference } & \multirow{2}{*}{ Disease } & \multirow{2}{*}{ Source } & \multicolumn{2}{|c|}{ Number } & \multirow{2}{*}{$\begin{array}{c}\text { Mean Age } \\
\text { (Range), Year }\end{array}$} & \multirow{2}{*}{$\begin{array}{c}\text { Route of } \\
\text { Administration }\end{array}$} & \multirow{2}{*}{ Number of Cells } & \multirow{2}{*}{$\begin{array}{l}\text { Number of } \\
\text { Treatments }\end{array}$} & \multirow{2}{*}{ Results } & \multirow{2}{*}{$\begin{array}{l}\text { Adverse } \\
\text { Events }\end{array}$} \\
\hline & & & Trial & Control & & & & & & \\
\hline Canesi et al. [89] & $\begin{array}{c}\text { Progressive } \\
\text { supranuclear } \\
\text { palsy } \\
\text { (Phase 1) }\end{array}$ & $\mathrm{BM}$ & 5 & 0 & $60-68$ & $\begin{array}{c}\text { IA (intra- } \\
\text { arterial) via } \\
\text { catheterization }\end{array}$ & $\begin{array}{c}1.7(1.2-2.0) \times \\
10^{6} / \mathrm{kg}\end{array}$ & 1 & $\begin{array}{l}\text { Clinical } \\
\text { stabilization for at } \\
\text { least } 6 \text { months } \\
\text { during the one-year } \\
\text { follow-up }\end{array}$ & $\begin{array}{l}\text { Transient left } \\
\text { hemiparesis }\end{array}$ \\
\hline Carstens et al. [90] & $\begin{array}{l}\text { Parkinson's } \\
\text { disease } \\
\text { (Case studies) }\end{array}$ & $\begin{array}{l}\text { AD } \\
\text { MSC-derived } \\
\text { stromal } \\
\text { vascular } \\
\text { fraction }\end{array}$ & 2 & 0 & 72,50 & $\begin{array}{l}\text { Facial and } \\
\text { nasal } \\
\text { transplantation }\end{array}$ & $6.0 \times 10^{7}$ cells & 1 & $\begin{array}{l}\text { Subjective } \\
\text { functional recovery } \\
\text { after } 2 \text { weeks and } \\
\text { up to } 5 \text { years }\end{array}$ & No \\
\hline
\end{tabular}

BM, bone marrow; AD, adipose.

\subsection{Traumatic Brain Injury}

Traumatic brain injury is one of the major serious diseases that threaten human life and health, causing traffic accidents, collisions with hard objects, and falls from high places. With improving medical technology, the survival rate of patients with traumatic brain injury has increased significantly. However, the prognosis for patients with severe TBI remains poor, such as disturbance of consciousness and motor disorder. The recent clinical reports using MSCs for the treatment of traumatic brain injury are summarized in Table 7. Wang et al. showed the results of a phase 2 clinical trial using UC-MSCs for traumatic brain injury patients [91]. Forty patients with sequelae of traumatic brain injury were randomly assigned to the stem cell treatment group or the control group, and UC-MSCs administration improved the neurological function and self-care in patients after 6 months. On the other hand, Tian et al. explored the clinical therapeutic effects and safety of autologous BM-MSCs therapy for traumatic brain injury by lumbar puncture [92]. The results showed improvement in the function of brain in the form of post-therapeutic improvements in consciousness and motor functions. In addition, they showed the age of patients and the time elapsed between injury and therapy had effects on the outcomes of the cellular therapy, and no correlation was found between the number of cell injections and improvements.

Table 7. Summary of recent clinical trials using MSCs for traumatic brain injury.

\begin{tabular}{|c|c|c|c|c|c|c|c|c|c|c|}
\hline \multirow{2}{*}{ Reference } & \multirow{2}{*}{ Disease } & \multirow{2}{*}{ Source } & \multicolumn{2}{|c|}{ Number } & \multirow{2}{*}{$\begin{array}{c}\text { Mean Age } \\
\text { (Range), Year }\end{array}$} & \multirow{2}{*}{$\begin{array}{c}\text { Route of } \\
\text { Administration }\end{array}$} & \multirow{2}{*}{ Number of Cells } & \multirow{2}{*}{$\begin{array}{l}\text { Number of } \\
\text { Treatments }\end{array}$} & \multirow{2}{*}{ Results } & \multirow{2}{*}{$\begin{array}{c}\text { Adverse } \\
\text { Events }\end{array}$} \\
\hline & & & Trial & Control & & & & & & \\
\hline Wang et al. [91] & $\begin{array}{l}\text { Traumatic } \\
\text { brain injury } \\
\text { (Phase 2) }\end{array}$ & $\mathrm{UC}$ & 20 & 20 & $\begin{array}{c}27.5 \pm 9.4 \\
28.6 \pm 10.1\end{array}$ & IT & $6.0 \times 10^{7}$ cells & 4 & $\begin{array}{l}\text { Comprehensive } \\
\text { functional recovery and } \\
\text { improvement in the ADL } \\
\text { after } 6 \text { months }\end{array}$ & $\begin{array}{l}\text { Mild } \\
\text { dizziness, } \\
\text { headache }\end{array}$ \\
\hline Tian et al. [92] & $\begin{array}{c}\text { Traumatic } \\
\text { brain injury }\end{array}$ & $\mathrm{BM}$ & 97 & 0 & - & IT & $3.0-5.0 \times 10^{6}$ cells & 1 & $\begin{array}{l}\text { Improvement of } \\
\text { consciousness and motor } \\
\text { function after } 14 \text { days }\end{array}$ & No \\
\hline
\end{tabular}

IT, intrathecal injection; BM, bone marrow; UC, Umbilical cord.

\section{Room for Improvement of MSCs Therapy and Future Perspectives}

Many clinical trials using several sources of MSCs for neurological disorders have been conducted mentioned above. There are many basic research studies using MSCs for the Huntington's disease model and Alzheimer's disease model [93]; however, little clinical trials are reported for these diseases. Now, clinical trials using MSCs for Huntington's disease and Alzheimer's disease are ongoing (ClinicalTrials.gov Identifier: NCT03252535, NCT04388982, NCT04040348, NCT02833792); therefore, the feasibility and efficacy of MSCs for Huntington's disease and Alzheimer's disease are expected.

Regarding allogeneity, autologous transplantation is thought to be desirable when considering the possibility of rejection, but this depends on the sources of MSCs. It would be difficult to isolate autologous BM- or AD-MSCs in infants and children with cerebral palsy compared to autologous MSC from UC and UCB, because BM and AD sampling involves invasive procedures. In contrast, collecting the autologous UC- and UCB-MSCs 
of adults is very difficult, because this would have required the cryopreservation of these cells decades ago.

As for the administration route, many clinical trials have adopted intrathecal and intravenous administration, with some papers having reported a significant difference in efficacy depending on the route of administration. The number of administration events is also important as the therapeutic effectiveness of intrathecal administration of MSCs is reported to be related to the levels of neurotrophic factor and anti-inflammatory cytokines in ALS patients. Therefore, the potential therapeutic effect of a single treatment with MSCs would not be long-lasting, because these cells gradually disappear in cerebrospinal fluid over time, meaning that multiple MSC administration events would be needed to sustain the therapeutic effects [74,77]. On the other hand, no correlation between the number of cell injections and improvements is also reported [92]. There is another problem that results from multiple MSCs injection. Five participants received multiple MSCs injection developed new class I anti-human leukocyte antigen (HLA) antibodies, which are associated with a specific lot of UC-MSCs or with a partial HLA match between donor and recipient [94]. These antibodies were reported to be clinically silent and not associated with any clinical manifestations to date. Therefore, it is important to further investigate the appropriate protocol for the administration of MSCs considering the sources, route, and number of times they are administered.

The paracrine factors secreted from MSCs seem to exert therapeutic effects rather than the actual differentiation of themselves [95]. Unlike cell therapies, the administration of exosomes derived from MSCs seems to have no risks of adverse effects such as cellular rejection and thrombosis. Additionally, different sources of MSCs have different exosome characteristics; therefore, it is necessary to select appropriate exosomes that contain enough neurotrophic factors such as BDNF, NGF, and HGF. Developing exosomes secreted from MSCs for clinical use have several challenges such as reliability, reproducibility, and robust techniques to isolate and purify therapeutic exosomes and to produce exosomes on a large scale with good manufacturing practices standards for clinical use [17]. Shekari et al. identified gaps in the current method of information gathering by systematically reviewing a substantial number of publications. They showed a lack of standards and poor consensus on different aspects of isolation processes; quantifications and tests of purity were important problems in the exosome-based therapies that made it difficult to compare reports [96]. Therefore, the translation of MSCs and exosomes of MSCs from the preclinical to clinical level presents several challenges to investigators and clinicians.

International large clinical trials using the same products for neurological disorders will be needed to establish suitable therapeutic protocol for the clinical use of MSCs and exosomes in the future.

\section{Conclusions}

Many existing therapies are insufficient in some cases for neurological disorders. Therefore, new alternative therapeutics are expected for the treatment of these neurological disorders. Recent clinical trials indicate that the use of MSCs as a new cell therapy is expected to be effective in combination with conventional rehabilitation and other medication. Furthermore, some clinical trials have been demonstrated the efficacy of exosome derived from MSCs and genetically modified neurotrophic factor-secreting MSCs for neurological disorders, which is a treatment method that can be expected to be very effective in the future (Figure 2).

The best-established protocol of MSCs therapy does not yet exist; however, many sources and many protocols of clinical trials will expand the potentials of the treatable area in neurological disorders and lead to established therapies. Further large clinical studies on using MSCs to treat neurological diseases will extend our knowledge of these cells in the future. 


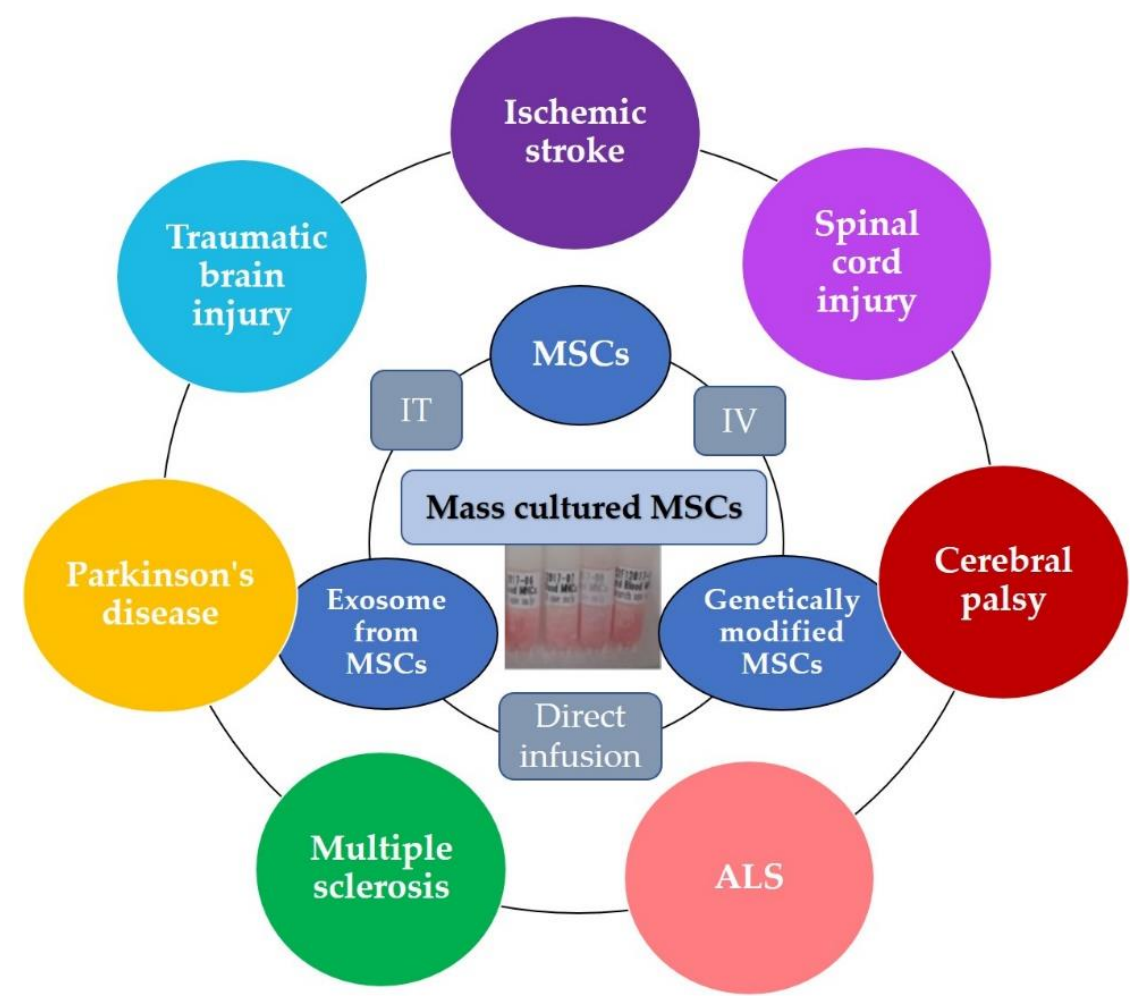

Figure 2. Therapeutic protocol of the clinical use of MSCs and exosomes for neurological disorders in the future.

Author Contributions: Conception and design of the study: T.M. and K.S. Acquisition of data: T.M. and K.S. Drafting or revising the manuscript: All authors. All authors have read and agreed to the published version of the manuscript.

Funding: This study was supported by Japan Society for the Promotion of Science (JSPS KAKENHI Grant Number 20K22892 and 21K15618).

Institutional Review Board Statement: Not applicable.

Informed Consent Statement: Not applicable.

Acknowledgments: The authors thank all members of the Department of Cell Processing and Transfusion, The Institute of Medical Science, The University of Tokyo for their help and consultation during this work.

Conflicts of Interest: The authors declare no conflict of interest.

\section{References}

1. Nagamura-Inoue, T.; Mukai, T. Umbilical Cord is a Rich Source of Mesenchymal Stromal Cells for Cell Therapy. Curr. Stem Cell Res. Ther. 2016, 11, 634-642. [CrossRef] [PubMed]

2. Caplan, A.I. Mesenchymal stem cells. J. Orthop. Res. Off. Publ. Orthop. Res. Soc. 1991, 9, 641-650. [CrossRef] [PubMed]

3. Gnecchi, M.; Melo, L.G. Bone marrow-derived mesenchymal stem cells: Isolation, expansion, characterization, viral transduction, and production of conditioned medium. Methods Mol. Biol. 2009, 482, 281-294. [CrossRef] [PubMed]

4. Bieback, K.; Kluter, H. Mesenchymal stromal cells from umbilical cord blood. Curr. Stem Cell Res. Ther. 2007, 2, 310-323. [CrossRef] [PubMed]

5. In't Anker, P.S.; Scherjon, S.A.; Kleijburg-van der Keur, C.; de Groot-Swings, G.M.; Claas, F.H.; Fibbe, W.E.; Kanhai, H.H. Isolation of mesenchymal stem cells of fetal or maternal origin from human placenta. Stem Cells 2004, 22, 1338-1345. [CrossRef] [PubMed]

6. Gruber, H.E.; Deepe, R.; Hoelscher, G.L.; Ingram, J.A.; Norton, H.J.; Scannell, B.; Loeffler, B.J.; Zinchenko, N.; Hanley, E.N.; Tapp, H. Human adipose-derived mesenchymal stem cells: Direction to a phenotype sharing similarities with the disc, gene expression profiling, and coculture with human annulus cells. Tissue Eng. Part A 2010, 16, 2843-2860. [CrossRef] [PubMed]

7. Chen, T.F.; Chen, K.W.; Chien, Y.; Lai, Y.H.; Hsieh, S.T.; Ma, H.Y.; Wang, K.C.; Shiau, C.Y. Dental Pulp Stem Cell-Derived Factors Alleviate Subarachnoid Hemorrhage-Induced Neuroinflammation and Ischemic Neurological Deficits. Int. J. Mol. Sci. 2019, 20, 3747. [CrossRef] [PubMed] 
8. Aliaghaei, A.; Boroujeni, M.E.; Ahmadi, H.; Bayat, A.H.; Tavirani, M.R.; Abdollahifar, M.A.; Pooyafar, M.H.; Mansouri, V. Dental pulp stem cell transplantation ameliorates motor function and prevents cerebellar atrophy in rat model of cerebellar ataxia. Cell Tissue Res. 2019, 376, 179-187. [CrossRef]

9. Dominici, M.; Le Blanc, K.; Mueller, I.; Slaper-Cortenbach, I.; Marini, F.; Krause, D.; Deans, R.; Keating, A.; Prockop, D.; Horwitz, E. Minimal criteria for defining multipotent mesenchymal stromal cells. The International Society for Cellular Therapy position statement. Cytotherapy 2006, 8, 315-317. [CrossRef] [PubMed]

10. Horwitz, E.M.; Le Blanc, K.; Dominici, M.; Mueller, I.; Slaper-Cortenbach, I.; Marini, F.C.; Deans, R.J.; Krause, D.S.; Keating, A.; International Society for Cellular Therapy. Clarification of the nomenclature for MSC: The International Society for Cellular Therapy position statement. Cytotherapy 2005, 7, 393-395. [CrossRef] [PubMed]

11. Nagamura-Inoue, T.; He, H. Umbilical cord-derived mesenchymal stem cells: Their advantages and potential clinical utility. World J. Stem Cells 2014, 6, 195-202. [CrossRef] [PubMed]

12. Weiss, M.L.; Anderson, C.; Medicetty, S.; Seshareddy, K.B.; Weiss, R.J.; VanderWerff, I.; Troyer, D.; McIntosh, K.R. Immune properties of human umbilical cord Wharton's jelly-derived cells. Stem Cells 2008, 26, 2865-2874. [CrossRef] [PubMed]

13. Seshareddy, K.; Troyer, D.; Weiss, M.L. Method to isolate mesenchymal-like cells from Wharton's Jelly of umbilical cord. Methods Cell Biol. 2008, 86, 101-119. [CrossRef]

14. Mukai, T.; Tojo, A.; Nagamura-Inoue, T. Mesenchymal stromal cells as a potential therapeutic for neurological disorders. Regen. Ther. 2018, 9, 32-37. [CrossRef]

15. Mukai, T.; Mori, Y.; Shimazu, T.; Takahashi, A.; Tsunoda, H.; Yamaguchi, S.; Kiryu, S.; Tojo, A.; Nagamura-Inoue, T. Intravenous injection of umbilical cord-derived mesenchymal stromal cells attenuates reactive gliosis and hypomyelination in a neonatal intraventricular hemorrhage model. Neuroscience 2017, 355, 175-187. [CrossRef]

16. Mukai, T.; Tojo, A.; Nagamura-Inoue, T. Umbilical Cord-Derived Mesenchymal Stromal Cells Contribute to Neuroprotection in Neonatal Cortical Neurons Damaged by Oxygen-Glucose Deprivation. Front. Neurol. 2018, 9, 466. [CrossRef] [PubMed]

17. Fuloria, S.; Subramaniyan, V.; Dahiya, R.; Dahiya, S.; Sudhakar, K.; Kumari, U.; Sathasivam, K.; Meenakshi, D.U.; Wu, Y.S.; Sekar, M.; et al. Mesenchymal Stem Cell-Derived Extracellular Vesicles: Regenerative Potential and Challenges. Biology 2021, 10, 172. [CrossRef]

18. Nakano, M.; Fujimiya, M. Potential effects of mesenchymal stem cell derived extracellular vesicles and exosomal miRNAs in neurological disorders. Neural Regen Res. 2021, 16, 2359-2366. [CrossRef]

19. Yu-Taeger, L.; Stricker-Shaver, J.; Arnold, K.; Bambynek-Dziuk, P.; Novati, A.; Singer, E.; Lourhmati, A.; Fabian, C.; Magg, J.; Riess, O.; et al. Intranasal Administration of Mesenchymal Stem Cells Ameliorates the Abnormal Dopamine Transmission System and Inflammatory Reaction in the R6/2 Mouse Model of Huntington Disease. Cells 2019, 8, 595. [CrossRef]

20. Sukhinich, K.K.; Namestnikova, D.D.; Gubskii, I.L.; Gabashvili, A.N.; Mel'nikov, P.A.; Vitushev, E.Y.; Vishnevskii, D.A.; Revkova, V.A.; Solov'eva, A.A.; Voitkovskaya, K.S.; et al. Distribution and Migration of Human Placental Mesenchymal Stromal Cells in the Brain of Healthy Rats after Stereotaxic or Intra-Arterial Transplantation. Bull. Exp. Biol. Med. 2020, 168, 542-551. [CrossRef] [PubMed]

21. Leong, K.H.; Zhou, L.L.; Lin, Q.M.; Wang, P.; Yao, L.; Huang, Z.T. Therapeutic effects of various methods of MSC transplantation on cerebral resuscitation following cardiac arrest in rats. Mol. Med. Rep. 2016, 13, 3043-3051. [CrossRef] [PubMed]

22. Xin, H.; Li, Y.; Buller, B.; Katakowski, M.; Zhang, Y.; Wang, X.; Shang, X.; Zhang, Z.G.; Chopp, M. Exosome-mediated transfer of miR-133b from multipotent mesenchymal stromal cells to neural cells contributes to neurite outgrowth. Stem Cells 2012, 30, 1556-1564. [CrossRef]

23. Han, M.; Cao, Y.; Xue, H.; Chu, X.; Li, T.; Xin, D.; Yuan, L.; Ke, H.; Li, G.; Wang, Z. Neuroprotective Effect of Mesenchymal Stromal Cell-Derived Extracellular Vesicles Against Cerebral Ischemia-Reperfusion-Induced Neural Functional Injury: A Pivotal Role for AMPK and JAK2/STAT3/NF-kB Signaling Pathway Modulation. Drug Des. Dev. Ther. 2020, 14, 2865-2876. [CrossRef]

24. Jiang, M.; Wang, H.; Jin, M.; Yang, X.; Ji, H.; Jiang, Y.; Zhang, H.; Wu, F.; Wu, G.; Lai, X.; et al. Exosomes from MiR-30d-5pADSCs Reverse Acute Ischemic Stroke-Induced, Autophagy-Mediated Brain Injury by Promoting M2 Microglial/Macrophage Polarization. Cell. Physiol. Biochem. Int. J. Exp. Cell. Physiol. Biochem. Pharmacol. 2018, 47, 864-878. [CrossRef] [PubMed]

25. Zhang, X.; Zhou, Y.; Li, H.; Wang, R.; Yang, D.; Li, B.; Fu, J. Intravenous administration of DPSCs and BDNF improves neurological performance in rats with focal cerebral ischemia. Int. J. Mol. Med. 2018, 41, 3185-3194. [CrossRef] [PubMed]

26. Wu, T.; Xu, W.; Chen, H.; Li, S.; Dou, R.; Shen, H.; Liu, X.; Liu, X.; Hong, Y.; He, J. Comparison of the differentiation of dental pulp stem cells and periodontal ligament stem cells into neuron-like cells and their effects on focal cerebral ischemia. Acta Biochim. Biophys. Sin. 2020, 52, 1016-1029. [CrossRef]

27. Lu, Y.; Zhou, Y.; Zhang, R.; Wen, L.; Wu, K.; Li, Y.; Yao, Y.; Duan, R.; Jia, Y. Bone Mesenchymal Stem Cell-Derived Extracellular Vesicles Promote Recovery Following Spinal Cord Injury via Improvement of the Integrity of the Blood-Spinal Cord Barrier. Front. Neurosci. 2019, 13, 209. [CrossRef] [PubMed]

28. Zhou, Y.; Wen, L.L.; Li, Y.F.; Wu, K.M.; Duan, R.R.; Yao, Y.B.; Jing, L.J.; Gong, Z.; Teng, J.F.; Jia, Y.J. Exosomes derived from bone marrow mesenchymal stem cells protect the injured spinal cord by inhibiting pericyte pyroptosis. Neural Regen. Res. 2022, 17, 194-202. [CrossRef] [PubMed]

29. Li, C.; Jiao, G.; Wu, W.; Wang, H.; Ren, S.; Zhang, L.; Zhou, H.; Liu, H.; Chen, Y. Exosomes from Bone Marrow Mesenchymal Stem Cells Inhibit Neuronal Apoptosis and Promote Motor Function Recovery via the Wnt/ $\beta$-catenin Signaling Pathway. Cell Transplant. 2019, 28, 1373-1383. [CrossRef] [PubMed] 
30. Sisa, C.; Kholia, S.; Naylor, J.; Herrera Sanchez, M.B.; Bruno, S.; Deregibus, M.C.; Camussi, G.; Inal, J.M.; Lange, S.; Hristova, M. Mesenchymal Stromal Cell Derived Extracellular Vesicles Reduce Hypoxia-Ischaemia Induced Perinatal Brain Injury. Front. Physiol. 2019, 10, 282. [CrossRef] [PubMed]

31. Thomi, G.; Surbek, D.; Haesler, V.; Joerger-Messerli, M.; Schoeberlein, A. Exosomes derived from umbilical cord mesenchymal stem cells reduce microglia-mediated neuroinflammation in perinatal brain injury. Stem Cell Res. Ther. 2019, 10, 105. [CrossRef] [PubMed]

32. Drommelschmidt, K.; Serdar, M.; Bendix, I.; Herz, J.; Bertling, F.; Prager, S.; Keller, M.; Ludwig, A.K.; Duhan, V.; Radtke, S.; et al. Mesenchymal stem cell-derived extracellular vesicles ameliorate inflammation-induced preterm brain injury. Brain Behav. Immun. 2017, 60, 220-232. [CrossRef]

33. Bonafede, R.; Turano, E.; Scambi, I.; Busato, A.; Bontempi, P.; Virla, F.; Schiaffino, L.; Marzola, P.; Bonetti, B.; Mariotti, R. ASC-Exosomes Ameliorate the Disease Progression in SOD1(G93A) Murine Model Underlining Their Potential Therapeutic Use in Human ALS. Int J. Mol. Sci 2020, 21, 3651. [CrossRef]

34. Corti, S.; Nizzardo, M.; Nardini, M.; Donadoni, C.; Salani, S.; Simone, C.; Falcone, M.; Riboldi, G.; Govoni, A.; Bresolin, N.; et al. Systemic transplantation of c-kit+ cells exerts a therapeutic effect in a model of amyotrophic lateral sclerosis. Hum. Mol. Genet. 2010, 19, 3782-3796. [CrossRef]

35. Marconi, S.; Bonaconsa, M.; Scambi, I.; Squintani, G.M.; Rui, W.; Turano, E.; Ungaro, D.; D'Agostino, S.; Barbieri, F.; Angiari, S.; et al. Systemic treatment with adipose-derived mesenchymal stem cells ameliorates clinical and pathological features in the amyotrophic lateral sclerosis murine model. Neuroscience 2013, 248, 333-343. [CrossRef]

36. Clark, K.; Zhang, S.; Barthe, S.; Kumar, P.; Pivetti, C.; Kreutzberg, N.; Reed, C.; Wang, Y.; Paxton, Z.; Farmer, D.; et al. Placental Mesenchymal Stem Cell-Derived Extracellular Vesicles Promote Myelin Regeneration in an Animal Model of Multiple Sclerosis. Cells 2019, 8, 1497. [CrossRef] [PubMed]

37. Riazifar, M.; Mohammadi, M.R.; Pone, E.J.; Yeri, A.; Lässer, C.; Segaliny, A.I.; McIntyre, L.L.; Shelke, G.V.; Hutchins, E.; Hamamoto, A.; et al. Stem Cell-Derived Exosomes as Nanotherapeutics for Autoimmune and Neurodegenerative Disorders. ACS Nano 2019, 13, 6670-6688. [CrossRef]

38. Choi, H.S.; Kim, H.J.; Oh, J.H.; Park, H.G.; Ra, J.C.; Chang, K.A.; Suh, Y.H. Therapeutic potentials of human adipose-derived stem cells on the mouse model of Parkinson's disease. Neurobiol. Aging 2015, 36, 2885-2892. [CrossRef]

39. Ahmed, H.H.; Salem, A.M.; Atta, H.M.; Eskandar, E.F.; Farrag, A.R.; Ghazy, M.A.; Salem, N.A.; Aglan, H.A. Updates in the pathophysiological mechanisms of Parkinson's disease: Emerging role of bone marrow mesenchymal stem cells. World J. Stem Cells 2016, 8, 106-117. [CrossRef]

40. Zhang, Y.; Zhang, Y.; Chopp, M.; Zhang, Z.G.; Mahmood, A.; Xiong, Y. Mesenchymal Stem Cell-Derived Exosomes Improve Functional Recovery in Rats After Traumatic Brain Injury: A Dose-Response and Therapeutic Window Study. Neurorehabil Neural Repair 2020, 34, 616-626. [CrossRef]

41. Xu, H.; Jia, Z.; Ma, K.; Zhang, J.; Dai, C.; Yao, Z.; Deng, W.; Su, J.; Wang, R.; Chen, X. Protective effect of BMSCs-derived exosomes mediated by BDNF on TBI via miR-216a-5p. Med. Sci. Monit. 2020, 26, e920855. [CrossRef]

42. Ruzicka, J.; Kulijewicz-Nawrot, M.; Rodrigez-Arellano, J.J.; Jendelova, P.; Sykova, E. Mesenchymal Stem Cells Preserve Working Memory in the 3xTg-AD Mouse Model of Alzheimer's Disease. Int J. Mol. Sci. 2016, 17, 152. [CrossRef] [PubMed]

43. Boutajangout, A.; Noorwali, A.; Atta, H.; Wisniewski, T. Human Umbilical Cord Stem Cell Xenografts Improve Cognitive Decline and Reduce the Amyloid Burden in a Mouse Model of Alzheimer's Disease. Curr. Alzheimer Res. 2017, 14, 104-111. [CrossRef]

44. Dey, N.D.; Bombard, M.C.; Roland, B.P.; Davidson, S.; Lu, M.; Rossignol, J.; Sandstrom, M.I.; Skeel, R.L.; Lescaudron, L.; Dunbar, G.L. Genetically engineered mesenchymal stem cells reduce behavioral deficits in the YAC 128 mouse model of Huntington's disease. Behav. Brain Res. 2010, 214, 193-200. [CrossRef]

45. Pollock, K.; Dahlenburg, H.; Nelson, H.; Fink, K.D.; Cary, W.; Hendrix, K.; Annett, G.; Torrest, A.; Deng, P.; Gutierrez, J.; et al. Human Mesenchymal Stem Cells Genetically Engineered to Overexpress Brain-derived Neurotrophic Factor Improve Outcomes in Huntington's Disease Mouse Models. Mol. Ther. 2016, 24, 965-977. [CrossRef] [PubMed]

46. Luzuriaga, J.; Polo, Y.; Pastor-Alonso, O.; Pardo-Rodríguez, B.; Larrañaga, A.; Unda, F.; Sarasua, J.R.; Pineda, J.R.; Ibarretxe, G. Advances and Perspectives in Dental Pulp Stem Cell Based Neuroregeneration Therapies. Int. J. Mol. Sci. 2021, $22,3564$. [CrossRef]

47. Nagpal, A.; Kremer, K.L.; Hamilton-Bruce, M.A.; Kaidonis, X.; Milton, A.G.; Levi, C.; Shi, S.; Carey, L.; Hillier, S.; Rose, M.; et al. TOOTH (The Open study Of dental pulp stem cell Therapy in Humans): Study protocol for evaluating safety and feasibility of autologous human adult dental pulp stem cell therapy in patients with chronic disability after stroke. Int. J. Stroke Off. J. Int. Stroke Soc. 2016, 11, 575-585. [CrossRef]

48. Chung, J.W.; Chang, W.H.; Bang, O.Y.; Moon, G.J.; Kim, S.J.; Kim, S.K.; Lee, J.S.; Sohn, S.I.; Kim, Y.H. Efficacy and Safety of Intravenous Mesenchymal Stem Cells for Ischemic Stroke. Neurology 2021, 96, e1012-e1023. [CrossRef] [PubMed]

49. Bhasin, A.; Kumaran, S.S.; Bhatia, R.; Mohanty, S.; Srivastava, M.V.P. Safety and Feasibility of Autologous Mesenchymal Stem Cell Transplantation in Chronic Stroke in Indian patients. A four-year follow up. J. Stem Cells Regen. Med. 2017, 13, 14-19. [CrossRef]

50. Bhasin, A.; Srivastava, M.V.; Mohanty, S.; Bhatia, R.; Kumaran, S.S.; Bose, S. Stem cell therapy: A clinical trial of stroke. Clin. Neurol. Neurosurg. 2013, 115, 1003-1008. [CrossRef] [PubMed]

51. Honmou, O.; Houkin, K.; Matsunaga, T.; Niitsu, Y.; Ishiai, S.; Onodera, R.; Waxman, S.G.; Kocsis, J.D. Intravenous administration of auto serum-expanded autologous mesenchymal stem cells in stroke. Brain 2011, 134, 1790-1807. [CrossRef] 
52. Qiao, L.Y.; Huang, F.J.; Zhao, M.; Xie, J.H.; Shi, J.; Wang, J.; Lin, X.Z.; Zuo, H.; Wang, Y.L.; Geng, T.C. A two-year follow-up study of cotransplantation with neural stem/progenitor cells and mesenchymal stromal cells in ischemic stroke patients. Cell Transplant. 2014, 23, S65-S72. [CrossRef]

53. Jiang, Y.; Zhu, W.; Zhu, J.; Wu, L.; Xu, G.; Liu, X. Feasibility of delivering mesenchymal stem cells via catheter to the proximal end of the lesion artery in patients with stroke in the territory of the middle cerebral artery. Cell Transplant. 2013, 22, 2291-2298. [CrossRef] [PubMed]

54. Vaquero, J.; Zurita, M.; Rico, M.A.; Aguayo, C.; Bonilla, C.; Marin, E.; Tapiador, N.; Sevilla, M.; Vazquez, D.; Carballido, J.; et al. Intrathecal administration of autologous mesenchymal stromal cells for spinal cord injury: Safety and efficacy of the $100 / 3$ guideline. Cytotherapy 2018, 20, 806-819. [CrossRef] [PubMed]

55. Hur, J.W.; Cho, T.H.; Park, D.H.; Lee, J.B.; Park, J.Y.; Chung, Y.G. Intrathecal transplantation of autologous adipose-derived mesenchymal stem cells for treating spinal cord injury: A human trial. J. Spinal Cord Med. 2016, 39, 655-664. [CrossRef]

56. Xiao, Z.; Tang, F.; Zhao, Y.; Han, G.; Yin, N.; Li, X.; Chen, B.; Han, S.; Jiang, X.; Yun, C.; et al. Significant Improvement of Acute Complete Spinal Cord Injury Patients Diagnosed by a Combined Criteria Implanted with NeuroRegen Scaffolds and Mesenchymal Stem Cells. Cell Transplant. 2018, 27, 907-915. [CrossRef] [PubMed]

57. Oh, S.K.; Choi, K.H.; Yoo, J.Y.; Kim, D.Y.; Kim, S.J.; Jeon, S.R. A Phase III Clinical Trial Showing Limited Efficacy of Autologous Mesenchymal Stem Cell Therapy for Spinal Cord Injury. Neurosurgery 2016, 78, 436-447. [CrossRef] [PubMed]

58. Vaquero, J.; Zurita, M.; Rico, M.A.; Aguayo, C.; Fernandez, C.; Rodriguez-Boto, G.; Marin, E.; Tapiador, N.; Sevilla, M.; Carballido, J.; et al. Cell therapy with autologous mesenchymal stromal cells in post-traumatic syringomyelia. Cytotherapy 2018, 20, 796-805. [CrossRef]

59. Vaquero, J.; Zurita, M.; Rico, M.A.; Bonilla, C.; Aguayo, C.; Fernández, C.; Tapiador, N.; Sevilla, M.; Morejón, C.; Montilla, J.; et al. Repeated subarachnoid administrations of autologous mesenchymal stromal cells supported in autologous plasma improve quality of life in patients suffering incomplete spinal cord injury. Cytotherapy 2017, 19, 349-359. [CrossRef] [PubMed]

60. Satti, H.S.; Waheed, A.; Ahmed, P.; Ahmed, K.; Akram, Z.; Aziz, T.; Satti, T.M.; Shahbaz, N.; Khan, M.A.; Malik, S.A. Autologous mesenchymal stromal cell transplantation for spinal cord injury: A Phase I pilot study. Cytotherapy 2016, 18, 518-522. [CrossRef] [PubMed]

61. Mendonça, M.V.; Larocca, T.F.; de Freitas Souza, B.S.; Villarreal, C.F.; Silva, L.F.; Matos, A.C.; Novaes, M.A.; Bahia, C.M.; de Oliveira Melo Martinez, A.C.; Kaneto, C.M.; et al. Safety and neurological assessments after autologous transplantation of bone marrow mesenchymal stem cells in subjects with chronic spinal cord injury. Stem Cell Res. Ther. 2014, 5, 126. [CrossRef] [PubMed]

62. Cheng, H.; Liu, X.; Hua, R.; Dai, G.; Wang, X.; Gao, J.; An, Y. Clinical observation of umbilical cord mesenchymal stem cell transplantation in treatment for sequelae of thoracolumbar spinal cord injury. J. Transl. Med. 2014, 12, 253. [CrossRef] [PubMed]

63. Dai, G.; Liu, X.; Zhang, Z.; Yang, Z.; Dai, Y.; Xu, R. Transplantation of autologous bone marrow mesenchymal stem cells in the treatment of complete and chronic cervical spinal cord injury. Brain Res. 2013, 1533, 73-79. [CrossRef] [PubMed]

64. Karamouzian, S.; Nematollahi-Mahani, S.N.; Nakhaee, N.; Eskandary, H. Clinical safety and primary efficacy of bone marrow mesenchymal cell transplantation in subacute spinal cord injured patients. Clin. Neurol. Neurosurg. 2012, 114, 935-939. [CrossRef]

65. Huang, L.; Zhang, C.; Gu, J.; Wu, W.; Shen, Z.; Zhou, X.; Lu, H. A Randomized, Placebo-Controlled Trial of Human Umbilical Cord Blood Mesenchymal Stem Cell Infusion for Children With Cerebral Palsy. Cell Transplant. 2018, 27, 325-334. [CrossRef] [PubMed]

66. Liu, X.; Fu, X.; Dai, G.; Wang, X.; Zhang, Z.; Cheng, H.; Zheng, P.; An, Y. Comparative analysis of curative effect of bone marrow mesenchymal stem cell and bone marrow mononuclear cell transplantation for spastic cerebral palsy. J. Transl. Med. 2017, 15, 48. [CrossRef] [PubMed]

67. Gu, J.; Huang, L.; Zhang, C.; Wang, Y.; Zhang, R.; Tu, Z.; Wang, H.; Zhou, X.; Xiao, Z.; Liu, Z.; et al. Therapeutic evidence of umbilical cord-derived mesenchymal stem cell transplantation for cerebral palsy: A randomized, controlled trial. Stem Cell Res. Ther. 2020, 11, 43. [CrossRef] [PubMed]

68. Ahn, S.Y.; Chang, Y.S.; Sung, S.I.; Park, W.S. Mesenchymal Stem Cells for Severe Intraventricular Hemorrhage in Preterm Infants: Phase I Dose-Escalation Clinical Trial. Stem Cells Transl. Med. 2018, 7, 847-856. [CrossRef]

69. Wang, X.; Hu, H.; Hua, R.; Yang, J.; Zheng, P.; Niu, X.; Cheng, H.; Dai, G.; Liu, X.; Zhang, Z.; et al. Effect of umbilical cord mesenchymal stromal cells on motor functions of identical twins with cerebral palsy: Pilot study on the correlation of efficacy and hereditary factors. Cytotherapy 2015, 17, 224-231. [CrossRef] [PubMed]

70. Wang, X.; Cheng, H.; Hua, R.; Yang, J.; Dai, G.; Zhang, Z.; Wang, R.; Qin, C.; An, Y. Effects of bone marrow mesenchymal stromal cells on gross motor function measure scores of children with cerebral palsy: A preliminary clinical study. Cytotherapy 2013, 15, 1549-1562. [CrossRef] [PubMed]

71. Berry, J.D.; Cudkowicz, M.E.; Windebank, A.J.; Staff, N.P.; Owegi, M.; Nicholson, K.; McKenna-Yasek, D.; Levy, Y.S.; Abramov, N.; Kaspi, H.; et al. NurOwn, phase 2, randomized, clinical trial in patients with ALS: Safety, clinical, and biomarker results. Neurology 2019, 93, e2294-e2305. [CrossRef] [PubMed]

72. Petrou, P.; Gothelf, Y.; Argov, Z.; Gotkine, M.; Levy, Y.S.; Kassis, I.; Vaknin-Dembinsky, A.; Ben-Hur, T.; Offen, D.; Abramsky, O.; et al. Safety and Clinical Effects of Mesenchymal Stem Cells Secreting Neurotrophic Factor Transplantation in Patients With Amyotrophic Lateral Sclerosis: Results of Phase 1/2 and 2a Clinical Trials. JAMA Neurol. 2016, 73, 337-344. [CrossRef] [PubMed] 
73. Syková, E.; Rychmach, P.; Drahorádová, I.; Konrádová, Š.; Růžičková, K.; Voří̌̌ek, I.; Forostyak, S.; Homola, A.; Bojar, M. Transplantation of Mesenchymal Stromal Cells in Patients With Amyotrophic Lateral Sclerosis: Results of Phase I/IIa Clinical Trial. Cell Transplant. 2017, 26, 647-658. [CrossRef] [PubMed]

74. Oh, K.W.; Moon, C.; Kim, H.Y.; Oh, S.I.; Park, J.; Lee, J.H.; Chang, I.Y.; Kim, K.S.; Kim, S.H. Phase I trial of repeated intrathecal autologous bone marrow-derived mesenchymal stromal cells in amyotrophic lateral sclerosis. Stem Cells Transl. Med. 2015, 4, 590-597. [CrossRef] [PubMed]

75. Staff, N.P.; Madigan, N.N.; Morris, J.; Jentoft, M.; Sorenson, E.J.; Butler, G.; Gastineau, D.; Dietz, A.; Windebank, A.J. Safety of intrathecal autologous adipose-derived mesenchymal stromal cells in patients with ALS. Neurology 2016, 87, 2230-2234. [CrossRef] [PubMed]

76. Rushkevich, Y.N.; Kosmacheva, S.M.; Zabrodets, G.V.; Ignatenko, S.I.; Goncharova, N.V.; Severin, I.N.; Likhachev, S.A.; Potapnev, M.P. The Use of Autologous Mesenchymal Stem Cells for Cell Therapy of Patients with Amyotrophic Lateral Sclerosis in Belarus. Bull. Exp. Biol. Med. 2015, 159, 576-581. [CrossRef] [PubMed]

77. Kim, H.Y.; Kim, H.; Oh, K.W.; Oh, S.I.; Koh, S.H.; Baik, W.; Noh, M.Y.; Kim, K.S.; Kim, S.H. Biological markers of mesenchymal stromal cells as predictors of response to autologous stem cell transplantation in patients with amyotrophic lateral sclerosis: An investigator-initiated trial and in vivo study. Stem Cells 2014, 32, 2724-2731. [CrossRef]

78. Mazzini, L.; Mareschi, K.; Ferrero, I.; Miglioretti, M.; Stecco, A.; Servo, S.; Carriero, A.; Monaco, F.; Fagioli, F. Mesenchymal stromal cell transplantation in amyotrophic lateral sclerosis: A long-term safety study. Cytotherapy 2012, 14, 56-60. [CrossRef] [PubMed]

79. Petrou, P.; Kassis, I.; Levin, N.; Paul, F.; Backner, Y.; Benoliel, T.; Oertel, F.C.; Scheel, M.; Hallimi, M.; Yaghmour, N.; et al. Beneficial effects of autologous mesenchymal stem cell transplantation in active progressive multiple sclerosis. Brain 2020, 143, 3574-3588. [CrossRef] [PubMed]

80. Riordan, N.H.; Morales, I.; Fernández, G.; Allen, N.; Fearnot, N.E.; Leckrone, M.E.; Markovich, D.J.; Mansfield, D.; Avila, D.; Patel, A.N.; et al. Clinical feasibility of umbilical cord tissue-derived mesenchymal stem cells in the treatment of multiple sclerosis. $J$. Transl. Med. 2018, 16, 57. [CrossRef] [PubMed]

81. Fernández, O.; Izquierdo, G.; Fernández, V.; Leyva, L.; Reyes, V.; Guerrero, M.; León, A.; Arnaiz, C.; Navarro, G.; Páramo, M.D.; et al. Adipose-derived mesenchymal stem cells (AdMSC) for the treatment of secondary-progressive multiple sclerosis: A triple blinded, placebo controlled, randomized phase I/II safety and feasibility study. PLoS ONE 2018, 13, e0195891. [CrossRef]

82. Harris, V.K.; Stark, J.; Vyshkina, T.; Blackshear, L.; Joo, G.; Stefanova, V.; Sara, G.; Sadiq, S.A. Phase I Trial of Intrathecal Mesenchymal Stem Cell-derived Neural Progenitors in Progressive Multiple Sclerosis. EBioMedicine 2018, 29, 23-30. [CrossRef]

83. Dahbour, S.; Jamali, F.; Alhattab, D.; Al-Radaideh, A.; Ababneh, O.; Al-Ryalat, N.; Al-Bdour, M.; Hourani, B.; Msallam, M.; Rasheed, M.; et al. Mesenchymal stem cells and conditioned media in the treatment of multiple sclerosis patients: Clinical, ophthalmological and radiological assessments of safety and efficacy. CNS Neurosci. Ther. 2017, 23, 866-874. [CrossRef] [PubMed]

84. Llufriu, S.; Sepúlveda, M.; Blanco, Y.; Marín, P.; Moreno, B.; Berenguer, J.; Gabilondo, I.; Martínez-Heras, E.; Sola-Valls, N.; Arnaiz, J.A.; et al. Randomized placebo-controlled phase II trial of autologous mesenchymal stem cells in multiple sclerosis. PLoS ONE 2014, 9, e113936. [CrossRef] [PubMed]

85. Li, J.F.; Zhang, D.J.; Geng, T.; Chen, L.; Huang, H.; Yin, H.L.; Zhang, Y.Z.; Lou, J.Y.; Cao, B.; Wang, Y.L. The potential of human umbilical cord-derived mesenchymal stem cells as a novel cellular therapy for multiple sclerosis. Cell Transplant. 2014, 23, S113-S122. [CrossRef]

86. Bonab, M.M.; Sahraian, M.A.; Aghsaie, A.; Karvigh, S.A.; Hosseinian, S.M.; Nikbin, B.; Lotfi, J.; Khorramnia, S.; Motamed, M.R.; Togha, M.; et al. Autologous mesenchymal stem cell therapy in progressive multiple sclerosis: An open label study. Curr. Stem Cell Res. Ther. 2012, 7, 407-414. [CrossRef]

87. Lee, P.H.; Lee, J.E.; Kim, H.S.; Song, S.K.; Lee, H.S.; Nam, H.S.; Cheong, J.W.; Jeong, Y.; Park, H.J.; Kim, D.J.; et al. A randomized trial of mesenchymal stem cells in multiple system atrophy. Ann. Neurol. 2012, 72, 32-40. [CrossRef]

88. Connick, P.; Kolappan, M.; Crawley, C.; Webber, D.J.; Patani, R.; Michell, A.W.; Du, M.Q.; Luan, S.L.; Altmann, D.R.; Thompson, A.J.; et al. Autologous mesenchymal stem cells for the treatment of secondary progressive multiple sclerosis: An open-label phase 2a proof-of-concept study. Lancet Neurol 2012, 11, 150-156. [CrossRef]

89. Canesi, M.; Giordano, R.; Lazzari, L.; Isalberti, M.; Isaias, I.U.; Benti, R.; Rampini, P.; Marotta, G.; Colombo, A.; Cereda, E.; et al. Finding a new therapeutic approach for no-option Parkinsonisms: Mesenchymal stromal cells for progressive supranuclear palsy. J. Transl. Med. 2016, 14, 127. [CrossRef]

90. Carstens, M.; Haq, I.; Martinez-Cerrato, J.; Dos-Anjos, S.; Bertram, K.; Correa, D. Sustained clinical improvement of Parkinson's disease in two patients with facially-transplanted adipose-derived stromal vascular fraction cells. J. Clin. Neurosci. 2020, 81, 47-51. [CrossRef]

91. Wang, S.; Cheng, H.; Dai, G.; Wang, X.; Hua, R.; Liu, X.; Wang, P.; Chen, G.; Yue, W.; An, Y. Umbilical cord mesenchymal stem cell transplantation significantly improves neurological function in patients with sequelae of traumatic brain injury. Brain Res. 2013, 1532, 76-84. [CrossRef] [PubMed]

92. Tian, C.; Wang, X.; Wang, X.; Wang, L.; Wang, X.; Wu, S.; Wan, Z. Autologous bone marrow mesenchymal stem cell therapy in the subacute stage of traumatic brain injury by lumbar puncture. Exp. Clin. Transplant. 2013, 11, 176-181. [CrossRef] 
93. Lo Furno, D.; Mannino, G.; Giuffrida, R. Functional role of mesenchymal stem cells in the treatment of chronic neurodegenerative diseases. J. Cell. Physiol. 2018, 233, 3982-3999. [CrossRef] [PubMed]

94. Sun, J.M.; Dawson, G.; Franz, L.; Howard, J.; McLaughlin, C.; Kistler, B.; Waters-Pick, B.; Meadows, N.; Troy, J.; Kurtzberg, J. Infusion of human umbilical cord tissue mesenchymal stromal cells in children with autism spectrum disorder. Stem Cells Transl. Med. 2020, 9, 1137-1146. [CrossRef] [PubMed]

95. Nooshabadi, V.T.; Mardpour, S.; Yousefi-Ahmadipour, A.; Allahverdi, A.; Izadpanah, M.; Daneshimehr, F.; Ai, J.; Banafshe, H.R.; Ebrahimi-Barough, S. The extracellular vesicles-derived from mesenchymal stromal cells: A new therapeutic option in regenerative medicine. J. Cell. Biochem. 2018, 119, 8048-8073. [CrossRef]

96. Shekari, F.; Nazari, A.; Assar Kashani, S.; Hajizadeh-Saffar, E.; Lim, R.; Baharvand, H. Pre-clinical investigation of mesenchymal stromal cell-derived extracellular vesicles: A systematic review. Cytotherapy 2021, 23, 277-284. [CrossRef] 